\title{
Experimental, modelling and simulation of an approach for optimizing the superplastic forming of Ti-6\% Al-4\% V Titanium alloy
}

\author{
A.O. Mosleh ${ }^{1,2}$, A.V. Mikhaylovskaya ${ }^{1}$, A.D. $\operatorname{Kotov}^{1}$, J.S. Kwame ${ }^{3}$ \\ ${ }^{1}$ National University of Science and Technology “MISiS”, Leninsky Prospekt, 4, Moscow 119049, \\ Russian Federation \\ ${ }^{2}$ Shoubra Faculty of Engineering, Benha University, Shoubra St. 108, Shoubra, P.O. 11629, Cairo, \\ Egypt. \\ 3 Advanced Forming Research Centre - University of Strathclyde, 85 Inchinnan Dr, Inchinnan, \\ Renfrew PA4 9LJ, United Kingdom
}

\begin{abstract}
The study presents an integrated approach for superplastic forming of Ti-6\% Al-4\%V titanium alloy. The flow behavior of the studied alloy was investigated using uniaxial constant strain rate tensile tests in a temperature range of $800-900{ }^{\circ} \mathrm{C}$ and a strain rate range of $3 \times 10-4-3 \times 10-3 \mathrm{~s}^{-1}$. The obtained flow behavior was modeled using the simple Johnson-Cook (S J-C), modified Johnson-Cook (M J-C) and artificial neural network (ANN) models. An assessment study between the constructed models was performed in order to evaluate the predictability of each model. Standard statistical comparative quantities such as correlation coefficient (R), mean absolute relative error (AARE) and the root mean square error (RMSE) were used to ascertain the model viability. The S J-C model proved ineffectual in predicting the flow behavior of Ti-6\% Al-4\% V alloy. The $\mathrm{M} \mathrm{J}-\mathrm{C}$ and ANN models are able to successfully describe the flow behavior of the alloy. The validity of the model used for the simulation was ascertained by testing the predicted data with the constructed models at a temperature of $875{ }^{\circ} \mathrm{C}$ and a strain rate of $2 \times 10-3 \mathrm{~s}^{-1}$ using DEFORM 3D finite element simulation (FES). The obtained results from the FES were verified with the experimental results after superplastic forming process. The FES results show the possibility of using uniaxial tensile test data to simulate superplastic forming process of the Ti- $6 \% \mathrm{Al}-4 \% \mathrm{~V}$ titanium sheets.
\end{abstract}

Keywords: Titanium alloys; Constitutive modeling; Johnson-Cook (J-C) models; Artificial neural network; Superplastic Forming; Finite elements analysis

Nomenclature

\begin{tabular}{|c|l|c|l|}
\hline S J-C & Simple Johnson-Cook & BP & Back- Propagation \\
\hline M J-C & Modified Johnson-Cook & $\dot{\varepsilon}^{*}$ & Dimensionless strain rate \\
\hline
\end{tabular}




\begin{tabular}{|c|l|c|l|}
\hline ANN & Artificial neural network & $\dot{\varepsilon}_{0}$ & Reference strain rate $\left(3 \times 10^{-4} \mathrm{~s}^{-1}\right)$ \\
\hline $\mathrm{R}$ & Correlation coefficient & $\mathrm{T}$ & Current temperature $\left({ }^{\circ} \mathrm{C}\right)$ \\
\hline AARE & Mean absolute relative error & $\mathrm{T}_{\mathrm{m}}$ & $\begin{array}{l}\text { Melting temperature of this alloy } \\
\left(1650{ }^{\circ} \mathrm{C}\right)\end{array}$ \\
\hline RMSE & Root mean square error & $T^{*}$ & Dimensionless temperature $\left({ }^{\circ} \mathrm{C}\right)$ \\
\hline FES & Finite element simulation & $\mathrm{T}_{\mathrm{r}}$ & Reference temperature $\left(800{ }^{\circ} \mathrm{C}\right)$ \\
\hline SPF & Superplastic forming & $\mathrm{B}, \mathrm{n}, \mathrm{C}_{1}$, and $\mathrm{m}$ & Material constants of S J-C model \\
\hline $\mathrm{A}$ & Titanium alpha-phase $(\mathrm{HCP})$ & $\mathrm{A}$ & Yield stress in S J-C model \\
\hline $\mathrm{B}$ & Titanium beta phase $(\mathrm{BCC})$ & $\begin{array}{c}\mathrm{A}_{1}, \mathrm{~B}_{1}, \mathrm{~B}_{2}, \mathrm{~B}_{3}, \\
\mathrm{C} \text { and } \lambda\end{array}$ & Material constants of M J-C model \\
\hline SEM & Scanning electron microscope & $\mathrm{Y}$ & Tested data value \\
\hline$\sigma$ & Flow stress $(\mathrm{MPa})$ & $Y_{\min }$ and $Y_{\max }$ & $\begin{array}{l}\text { The min. and max. values in tested } \\
\text { data }\end{array}$ \\
\hline$\varepsilon$ & True strain & $W$ & Related value of Y \\
\hline$\dot{\varepsilon}$ & Current strain rate $\left(\mathrm{s}^{-1}\right)$ & $\mathrm{P}_{1,2, . ., 7}$ & Tracking points \\
\hline
\end{tabular}

\section{Introduction}

Titanium alloys are widely used in many life-fields such as aerospace, chemical industry, military, biomedical, energy production, marine industry, architecture and transportation. The distinct properties of titanium alloys like their high strength-to-weight ratio, excellent corrosion resistance and low elastic modulus makes them the preferred choice for these applications. However, the main issue restricting the broader adoption of these alloys is the difficulty of their formability at room temperature. Superplastic forming (SPF) offers a viable approach for forming titanium alloys with complex shapes under low flow stresses in a single step. SPF technique mainly helps in curtailing manufacturing cycle, reduces component weight and also offers low residual stress [1-4]. Generally, a holistic understanding of the flow behavior of metallic alloys at high temperature is a challenging and complex endeavor. Mathematical modeling and finite element simulation (FES) offer alternative routes to understanding material behavior and are the main approaches utilized in this research to examine the sheet metal formability. These approaches play major roles especially during experimental process design optimization with the potential of reducing material cost by way of minimizing the quantity of materials needed for experimental trials. Extensive research has been done on the superplasticity of titanium alloys with most works focused on Ti-6\%Al-4\% V alloy [5-18]. However, a limited amount of research works has been carried out, to clarify the integration between flow behavior modeling, FES, and SPF processes. Mostly, constitutive models are utilized to characterize the influence of strain, strain rate, and temperature on the flow behavior of metallic materials at elevated temperatures. Generally, constitutive models are divided into the physics-based [19], phenomenological constitutive [20,21] and artificial neural network (ANN) [22] models. Johnson-Cook $(\mathrm{J}-\mathrm{K})$ and Arrhenius models are phenomenological classes. 


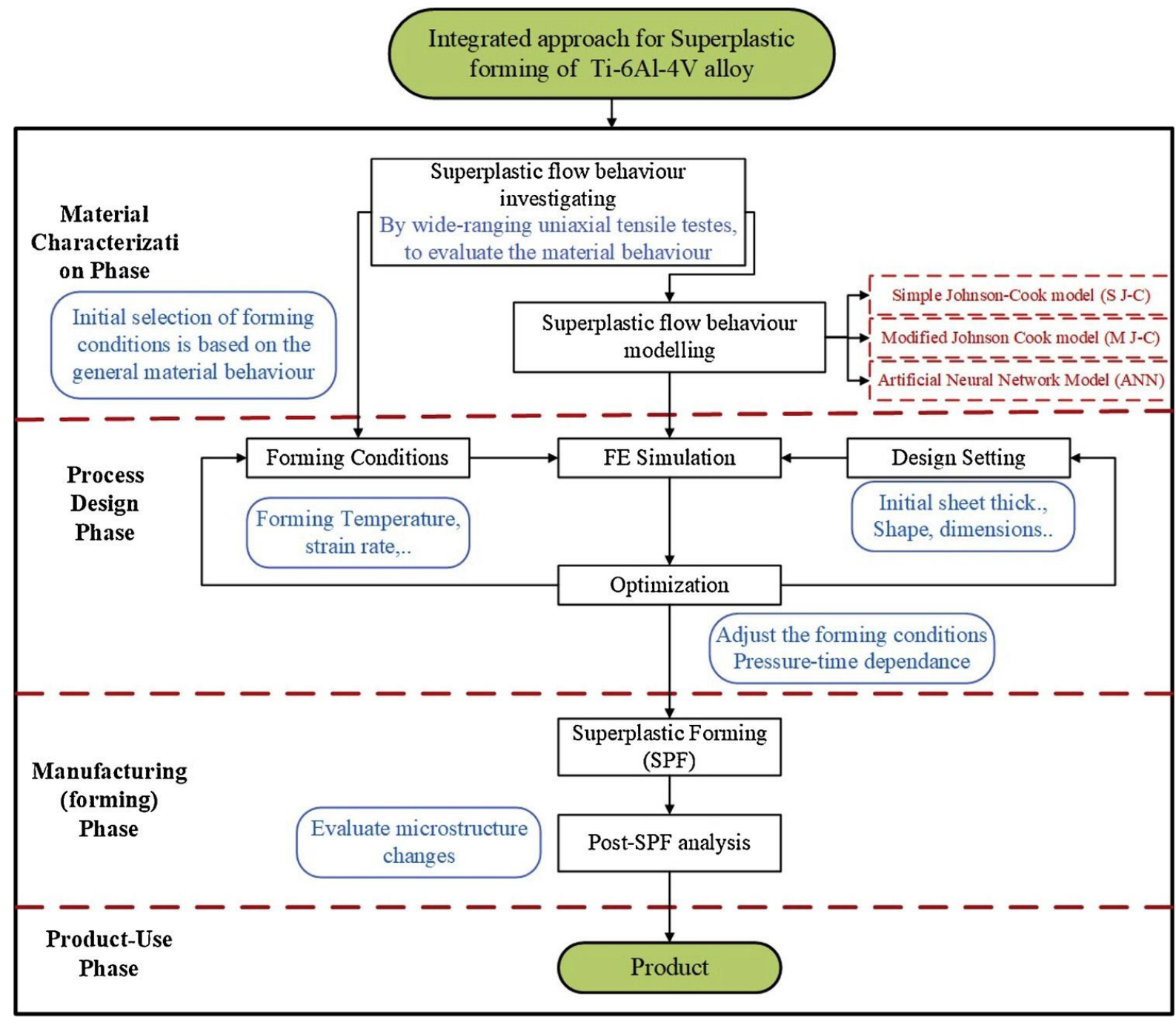

Fig. 1. Schematic of the integrated approach for SPF of investigated alloy

In the J-C model, strain rate hardening, strain hardening, and thermal softening are assumed to be the three independent phenomena [23,24]. ANN models provide the possibility to mathematically model complex functions. ANNs are widely used due to their ability to model relations between investigated variables without knowing the physical model of the phenomena. ANN usually provides better correlated and fitted results than those obtained from classical mathematical models. The sequences of ANN modelling are: (a) collecting the initial data after tensile tests, (b) defining the inlet/ target factors, (c) studying and pre-treatment of the tested data, (d) training of ANN, (e) approval of the trained model and (f) performance evaluation of the proposed model [2536]. In general, FES is used to optimize forming processes by projecting a better understanding of the chosen forming parameters [37]. FES modelling saves time and materials increases die life as well as reduces manufacturing cost. Complex shapes with large strains and nonlinear flow behavior of materials can be evaluated effectively and quickly with FES [38-40]. Sorgente et al. [37] showed that, FE simulations could be mainly utilized in SPF applications for process optimization purposes. Giuliano [39] proposed four-node, isoperimetric and arbitrary quadrilateral elements for FES in Ti- 
$6 \% \mathrm{Al}-4 \% \mathrm{~V}$ alloy. Chen et al. [40] used the continuous sequence element for successful FES in the same alloy. The main objective of this study is to develop an integrated approach for superplastic forming of Ti-6\%Al-4\% V alloy. The various steps utilized includes; (1) material characterization via flow behavior analysis after constant strain rates tests, (2) flow behavior modeling using an appropriate constitutive model, (3) finite element analysis for assessing the forming parameters and optimizing the forming process, (4) superplastic forming and (5) the post-superplastic forming analysis. In the post-SPF step, the microstructure at the critical sections was analyzed. A comparative study using R, AARE and RMSE statistical terms were performed in order to validate the constructed models. The validated models were used for predicting the un-tested conditions which also offers potential advantages in terms of material cost cutback and time reduction.

\section{Materials and test experiments}

The integrated approach for superplastic forming process used in the current work is described by Fig. 1. The flow behavior of the conventional Ti-6\% $\mathrm{Al}-4 \% \mathrm{~V}$ sheets was investigated using uniaxial tensile tests with constant strain rates. The tested strain rate and temperature ranges were $3 \times 10-4-3 \times 10-3 \mathrm{~s}-1$

and $800-900{ }^{\circ} \mathrm{C}$, respectively. These ranges are identified with superplastic deformation behavior [21]. In the as-processed state, the microstructure of the investigated Ti-6\% Al- 4\%V alloy exhibited two-phase structure with $\alpha$ (dark) and $\beta$ (bright) phases (Fig. 2a). The $\alpha$ - and $\beta$-grain sizes are $2.4 \pm$ $0.3 \mu \mathrm{m}$ and $1.6 \pm 0.3 \mu \mathrm{m}$, respectively. The dog-bone type samples cut parallel to the sheet rolling direction were tested via a uniaxial tensile test method (Fig. 2b). The uniaxial tensile tests were performed at constant strain rate using a Walter-Bay LFM 100 test machine. The true stress- strain data were used to construct the simple Johnson-Cook (S J-C), modified Johnson-Cook (M J-C) and artificial neural network (ANN) models in order to fit and predict the flow behavior of the investigated alloy. The experimental and predicted data were fed into a FES program to optimize the real mechanical behavior of the investigated alloy. A DEFORM 3D FES software was utilized to optimize the superplastic forming (SPF) process of the investigated alloy. The specimen with an initial thickness of $1 \mathrm{~mm}$ was tetrahedrally meshed into 100,000 elements (Fig. 2c). The forming process was simulated via a plane strain scheme. Through the process, the material blank was placed on the bottom die. A clamping force of 3 tons was applied to ensure the fixation of the upper and lower dies and also to prevent leakage of the forming gas. Argon was used as a forming gas to avoid oxidation during the process. Gas pressure was applied to the upper surface of the sample. The gas pressure versus time relation, which is a function of the optimum constant strain rate was calculated. The shear frictional law was used and the friction factor of 0.7 was set during the simulation process. The temperature of the specimen and the dies were kept constant at $875^{\circ} \mathrm{C}$. Based on the FES results, the SPF process was performed using a superplastic forming lab machine at a temperature of $875{ }^{\circ} \mathrm{C}$ (Fig. 2d). An initial strain rate of $2 \times 10-3 \mathrm{~s}-1$ was used prior to the superplastic forming process. The 
forming die was selected as current shape since this shape is considered to be complex and have several critical points which corresponded to high and low strain rates. This aided in the analysis of the strain rate evolution at these critical points and also provided a good understanding of the forming process for complex shapes. The microstructure of parts after the superplastic forming process was analyzed in the critical points corresponding with the maximum strain values. For microstructure analysis, the mechanically grinded and polished samples were etched in Kroll's agent and characterized using an SEM microscope, Tescan-VEGA LMH TESCAN Brno, s.r.o., (Kohoutovice, Czech Republic).

(a)

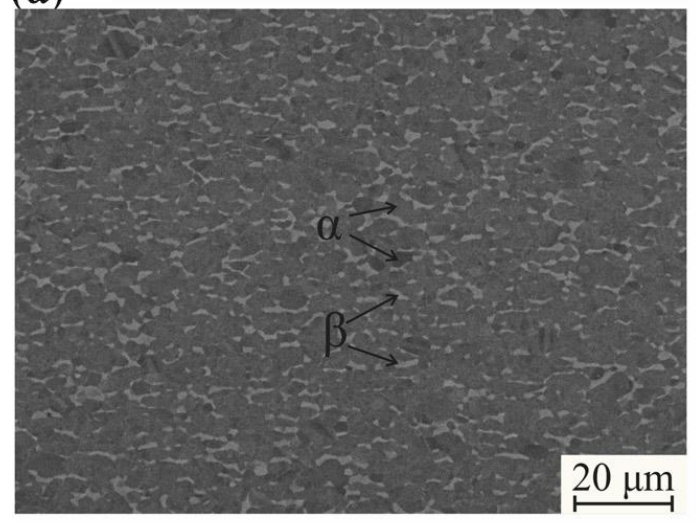

(b)

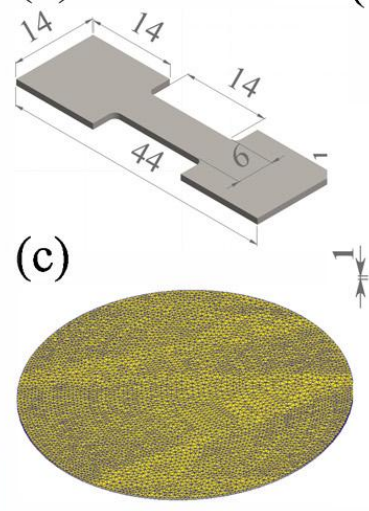

(d) Forming gas inlet

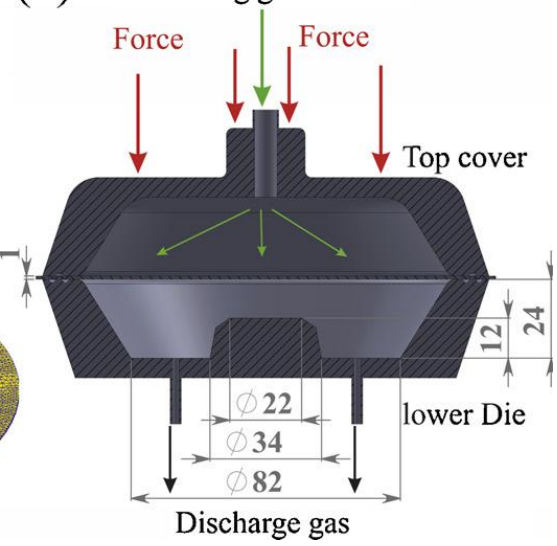

Fig. 2. (a) The initial microstructure of the investigated Ti- $6 \% \mathrm{Al}-4 \% \mathrm{~V}$ alloy, (b) the dimensions of the dog-bone uniaxial tensile sample, (c) the meshed blank specimen surface, (d) drafting with general dimensions of the forming die cavity.

\section{Results and discussion}

\subsection{Constant strain rate test results}

Fig. 3 illustrates the true stress- strain curves of Ti-6\%Al-4\% $\mathrm{V}$ alloy obtained from the uniaxial tensile test conducted at constant strain rates. The main characteristic of the flow behavior of the alloy is the strain hardening phenomenon (Fig. 3a-d), except for stress-strain curves at $3 \times 10-3 \mathrm{~s}-1$ and temperatures of $800-850{ }^{\circ} \mathrm{C}$ (Fig. 3a-c), which demonstrate strain softening. It was observed that the peak stress values increased with increasing strain rate and decreasing temperature. The choice of forming temperature and strain rate combinations for this alloy is very complicated. Choosing lower temperature and higher strain rate, which are economical for forming, leads to high forming stress and low strain. For low forming stress, high temperature and low strain rate should be used, but this leads to more forming time and grain growth. For this alloy, the most suitable forming temperature range which provides low forming stress and high elongation is $825-875^{\circ} \mathrm{C}$ [7]. The obtained data were utilized to construct the S J-C, M J-C and ANN models for fitting and predicting the flow behavior of 
the studied alloy. In this study, $875^{\circ} \mathrm{C}$ was selected for the superplastic forming tests to minimize the required forming gas pressure.
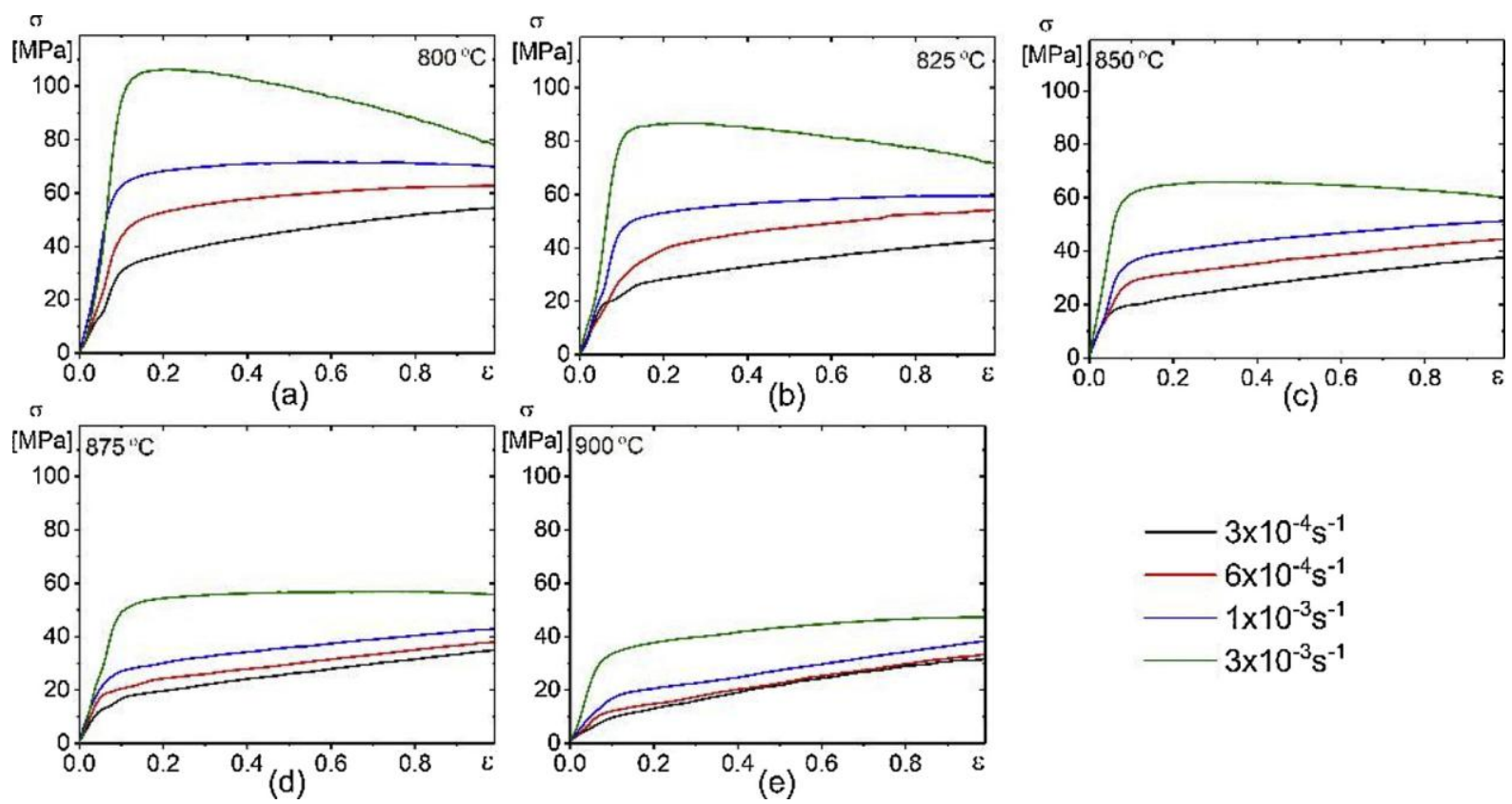

Fig. 3. True stress vs true strain of Ti-6\% $\mathrm{Al}-4 \% \mathrm{~V}$ titanium alloy at various strain rate and temperatures: (a) $800{ }^{\circ} \mathrm{C}$, (b) $825^{\circ} \mathrm{C}$, (c) $850{ }^{\circ} \mathrm{C}$, (d) $875^{\circ} \mathrm{C}$ and (e) $900{ }^{\circ} \mathrm{C}$.

\subsection{Superplastic flow behavior modelling}

\subsubsection{Simple Johnson-Cook model (S J-C)}

The flow behavior of Ti-6\% $\mathrm{Al}-4 \% \mathrm{~V}$ alloy can be predicted during superplastic deformation process using (S J-C) model. It involves the separation of the strain rate hardening, strain hardening and thermal softening from each other. The (S J-C) model can be expressed as follows Eq. 1,

$$
\sigma=\left(A+B \varepsilon^{n}\right)\left(1+C_{1} \ln \dot{\varepsilon}^{*}\right)\left(1-T^{* m}\right)
$$

The definitions of each term are listed in Table 1.

In the current work, the reference strain rate and temperature were taken as $3 \times 10^{-4} \mathrm{~s}^{-1}$ and $800{ }^{\circ} \mathrm{C}$, respectively.

Table 1. Terms definition and constants of Johnson-Cook model.

\begin{tabular}{|c|l|c|l|}
\hline$\left(A+B \varepsilon^{n}\right)$ & \multicolumn{1}{|c|}{ Strain hardening impact } & $\dot{\varepsilon}$ & The current strain rate \\
\hline$\left(1+C_{1} \ln \dot{\varepsilon}^{*}\right)$ & $\begin{array}{l}\text { Strain rate hardening } \\
\text { impact }\end{array}$ & $T^{*}=\frac{\left(T-T_{r}\right)}{\left(T_{m}-T_{r}\right)}$ & The dimensionless temperature \\
\hline$\left(1-T^{* m}\right)$ & Thermal softening impact & $\mathrm{T}_{\mathrm{m}}$ & Melting temperature for this alloy \\
\hline
\end{tabular}




\begin{tabular}{|c|l|c|l|}
\hline & & & $\left(\right.$ is equal to $\left.1650{ }^{\circ} \mathrm{C}\right)$ \\
\hline$\sigma$ & Flow stress & $\mathrm{T}$ & Current absolute temperature \\
\hline$\varepsilon$ & True strain & $\mathrm{T}_{\mathrm{r}}$ & Reference temperature \\
\hline$\dot{\varepsilon}^{*}=\dot{\varepsilon} / \dot{\varepsilon}_{0}$ & Dimensionless strain rate & $\mathrm{A}$ & $\begin{array}{l}\text { Yield stress at reference } \\
\text { conditions }\end{array}$ \\
\hline$\dot{\varepsilon}_{0}$ & The reference strain rate & $\mathrm{B}, \mathrm{n}, \mathrm{C}_{1,}$ and $\mathrm{m}$ & Material constants of $\mathrm{J}-\mathrm{C}$ model. \\
\hline
\end{tabular}

\subsubsection{A, B and $\mathrm{n}$ determination.}

The material constants $\mathrm{A}, \mathrm{B}$ and $\mathrm{n}$ were determined by ignoring the thermal softening and strain rate hardening at the reference conditions $\left(3 \times 10^{-4} \mathrm{~s}^{-1}\right.$ and $\left.800^{\circ} \mathrm{C}\right)$, Eq. 1 can be rewritten as Eq. 2 ,

$$
\sigma=A+B \varepsilon^{n} \Rightarrow \ln (\sigma-A)=\ln B+n \ln \varepsilon
$$

From the experimental results, the yield stress at the reference condition $\left(3 \times 10^{-4} \mathrm{~s}^{-1}\right.$ and $\left.800{ }^{\circ} \mathrm{C}\right)$ was $31 \mathrm{MPa}$ (Fig. 3). Fig. 4 illustrates the linear relation between $\ln (\sigma-\mathrm{A})$ and $\ln \varepsilon$. Therefore, the $\mathrm{B}$ and $\mathrm{n}$ can be acquired from the slop and intercept respectively. These values were $\mathrm{B}=24.11, \mathrm{n}=0.808$ (Fig. 4). condition $\left(3 \times 10^{-4} \mathrm{~s}^{-1}\right.$ and $\left.800^{\circ} \mathrm{C}\right)$ was $31 \mathrm{MPa}$ (Fig. 3). Fig. 4 illustrates the linear relation between $\ln (\sigma-\mathrm{A})$ and $\ln \varepsilon$. Therefore, the B and $\mathrm{n}$ can be acquired from the slop and intercept respectively. These values were $B=24.11, n=0.808$ (Fig. 4).

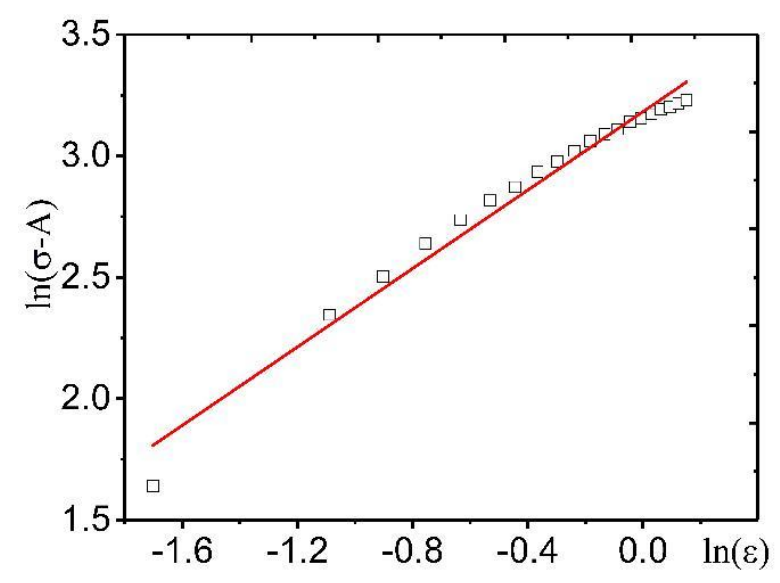

Fig. 4. Dependence of $\ln (\sigma-\mathrm{A})$ versus $\ln \varepsilon$

\subsubsection{C1 determination.}

$\mathrm{C} 1$ was determined by ignoring the thermal softening term at the reference temperature $\left(800{ }^{\circ} \mathrm{C}\right)$, thus, Eq. 1 can be expressed as Eq. 3,

$$
\sigma=\left(A+B \varepsilon^{n}\right)\left(1+C_{1} \ln \dot{\varepsilon}^{*}\right) \Rightarrow \frac{\sigma}{\left(A+B \varepsilon^{n}\right)}-1=C_{1} \ln \dot{\varepsilon}^{*}
$$


Based on Eq. 3, the values of $C_{1}$ can be computed from the slop of the fitted lines in $\left(\frac{\sigma}{\left(A+B \varepsilon^{n}\right)}-1\right)-$ $\ln \dot{\varepsilon}^{*}$ graph at a strain range of 0.1 to 1 (Fig. 5a). Fig. $5 \mathrm{~b}$ shows the values of $\mathrm{C}_{1}$ on the fitted curve vs strain. The $\mathrm{C}_{1}$ values are regressed by Eq. 4 .

$$
C_{1}=1.164-1.55 \varepsilon+0.86 \varepsilon^{2}-0.31 \varepsilon^{3}
$$

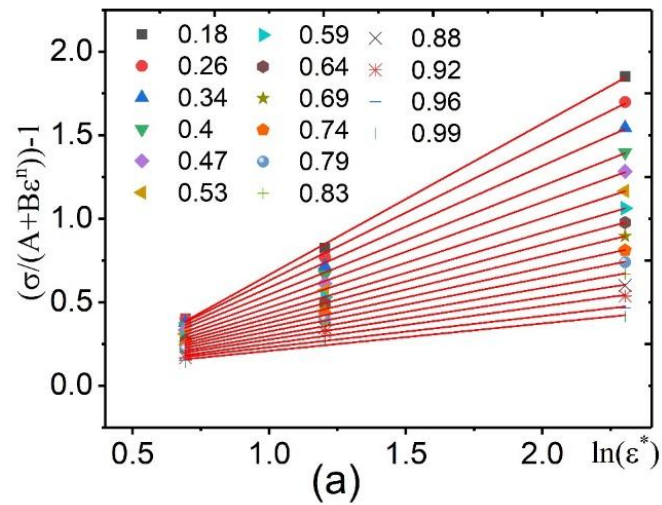

(a)

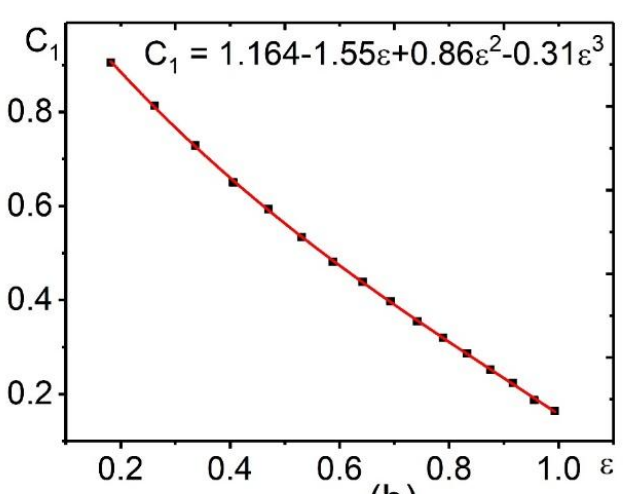

(b)

Fig. 5. (a) Relationship between $\frac{\sigma}{\left(A+B \varepsilon^{n}\right)}-1$ and $\ln \dot{\varepsilon}^{*}$ for strains from 0.1 to 1 and (b) strain dependence of $\mathrm{C}_{1}$.

\subsubsection{3. m determination.}

At the reference strain rate of $3 \times 10-4 \mathrm{~s}^{-1}$, the thermal softening effect on flow stress could be isolated. So, Eq. 1 can be described as Eq. 5 to determine the constant $\mathrm{m}$.

$$
\sigma=\left(A+B \varepsilon^{n}\right)\left(1-T^{* m}\right) \Rightarrow 1-\frac{\sigma}{\left(A+B \varepsilon^{n}\right)}=T^{* m} \Rightarrow \ln \left(1-\frac{\sigma}{\left(A+B \varepsilon^{n}\right)}\right)=m \ln T^{*}
$$

The dependence of $\ln \left(1-\frac{\sigma}{\left(A+B \varepsilon^{n}\right)}\right)$ vs $\ln T^{*}$ is shown in Fig. 6a. The m-values are computed from the slope of the fitted lines at different strain and the m vs strain data were fitted (Fig. 6b) by Eq. 6.

$$
m=0.82-0.67 \varepsilon+0.29 \varepsilon^{2}+0.04 \varepsilon^{3}
$$

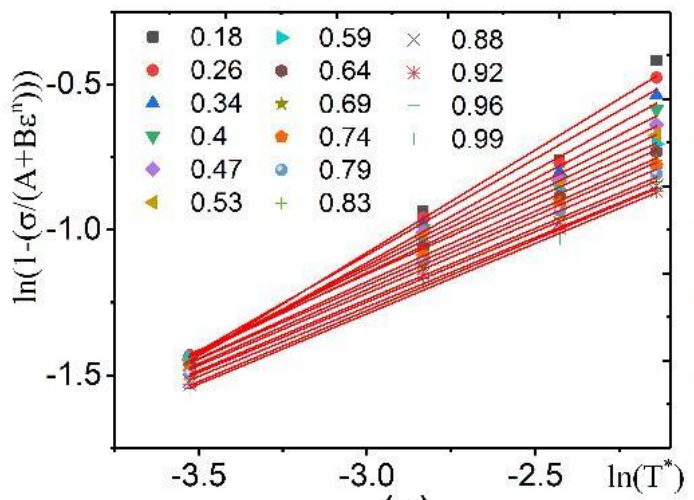

(a)

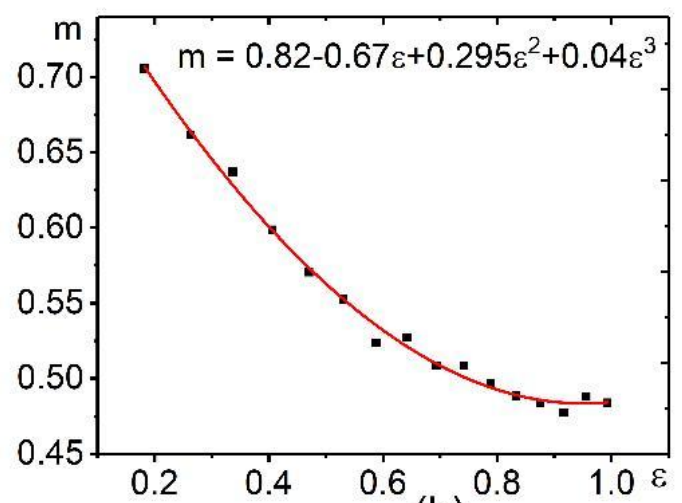

(b) 
Fig. 6 (a) Relationship between $\ln \left(1-\frac{\sigma}{\left(A+B \varepsilon^{n}\right)}\right)$ and $\ln T^{*}$ for strains of 0.1 to 1 and (b) strain dependence of $m$.

Therefore, the (S J-C) model for Ti-6\%Al-4\%V can be computed as follows Eq. 7,

$$
\left\{\begin{array}{l}
\sigma=\left(30+24.11 \varepsilon^{0.808}\right)\left(1+C_{1} \ln \dot{\varepsilon}^{*}\right)\left(1-T^{* m}\right) \\
C_{1}=1.24-1.96 \varepsilon+1.47 \varepsilon^{2}-0.58 \varepsilon^{3} \\
m=0.82-0.67 \varepsilon+0.29 \varepsilon^{2}+0.04 \varepsilon^{3}
\end{array}\right.
$$

Fig. 7 shows the comparison between the experimental and predicted data by Eq. 7. The quality of the proposed simple J-C model was appraised by using standard statistical quantities Eqs. 8, 9 and 10.

Correlation coefficient $(R)=\frac{\sum_{i=1}^{N}\left(\sigma_{i}-\bar{\sigma}\right)\left(P_{i}-\bar{P}\right)}{\sqrt{\sum_{i=1}^{N}\left(\sigma_{i}-\bar{\sigma}\right)^{2} \sum_{i=1}^{N}\left(P_{i}-\bar{P}\right)^{2}}}$

Average absolute relative error $(A A R E)=\frac{1}{N} \sum_{i=1}^{N}\left|\frac{\sigma_{i}-P_{i}}{\sigma_{i}}\right|$

Root mean square error $(R M S E)=\sqrt{\frac{1}{N} \sum_{i=1}^{N}\left(\sigma_{i}-P_{i}\right)^{2}}$

Where $\sigma_{i}$ and $P_{i}$ are the experimental and predicted flow stress values, respectively. $\bar{\sigma}, \bar{P}$ and $N$ are the average experimental flow stress, the average predicted flow stress and the sample data size, respectively.

The correlation coefficient (R), the average absolute relative error (AARE), and the root mean square error (RMSE) were $80 \%, 26 \%$, and 13.2, respectively. The level of obtained errors revealed that, the simple Johnson-Cook model is unsuitable for predicting the flow behavior of the investigated alloy.
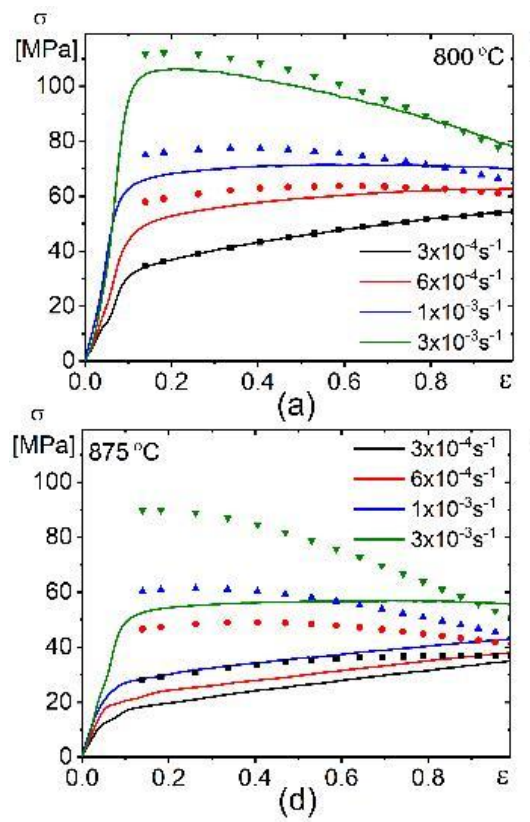
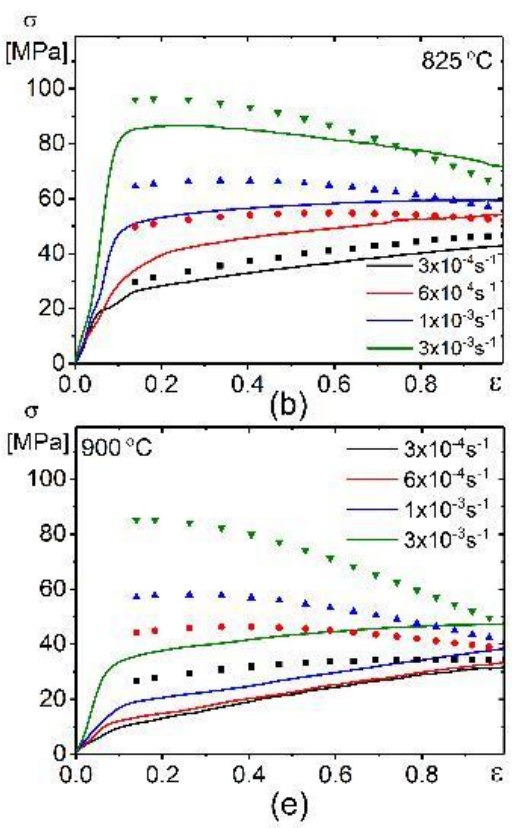
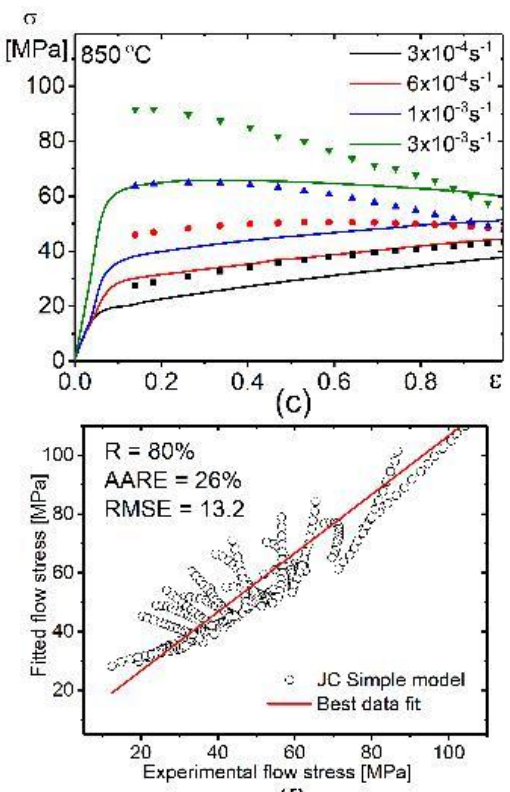

(f) 
Fig. 7. Comparative plots for the experimental results (lines) and fitted values of S J-C model (symbols) at various strain rates and temperatures; (a) $800{ }^{\circ} \mathrm{C}$, (b) $825^{\circ} \mathrm{C}$, (c) $850{ }^{\circ} \mathrm{C}$, (d) $875^{\circ} \mathrm{C}$, (e) $900{ }^{\circ} \mathrm{C}$ and (f) the correlation between experimental and fitted flow stress.

\subsubsection{Modified Johnson Cook model (M J-C)}

An M J-C model was also constructed to fit and predict the flow behavior of Ti$6 \% \mathrm{Al}-4 \% \mathrm{~V}$ alloy by Eq. 11.

$\sigma=\left(A_{1}+B_{1} \varepsilon+B_{2} \varepsilon^{2}+B_{3} \varepsilon^{3}\right)\left(1+C \ln \dot{\varepsilon}^{*}\right)\left(e^{\lambda\left(T-T_{r}\right)}\right)$

Where $A_{1}, B_{1}, B_{2}, B_{3}, C$ and $\lambda$ are the material constants. Again, the reference strain rate and temperature were considered as $3 \times 10^{-4} \mathrm{~s}^{-1}$ and $800{ }^{\circ} \mathrm{C}$, respectively.

\subsubsection{1. $\mathrm{A} 1, \mathrm{~B} 1, \mathrm{~B} 2$ and $\mathrm{B} 3$ determination}

Using the same analogy as in the case of $\mathrm{S} \mathrm{J}-\mathrm{C}$ model, $\mathrm{A}_{1}, \mathrm{~B}_{1}, \mathrm{~B}_{2}$ and $\mathrm{B}_{3}$ were determined by ignoring the terms of the thermal softening and strain rate hardening at $3 \times 10^{-}$ ${ }^{4} \mathrm{~s}^{-1}$ and $800{ }^{\circ} \mathrm{C}$ (reference conditions). Therefore, Eq. 11 can be expressed as Eq. 12,

$$
\sigma=A_{1}+B_{1} \varepsilon+B_{2} \varepsilon^{2}+B_{3} \varepsilon^{3}
$$

The values of $A_{1}, B_{1}, B_{2}$ and $B_{3}$ were computed as 29.19, 42.7, -21.4, and 4, respectively, using the stress-strain curve at reference conditions, as shown in Fig. 8.

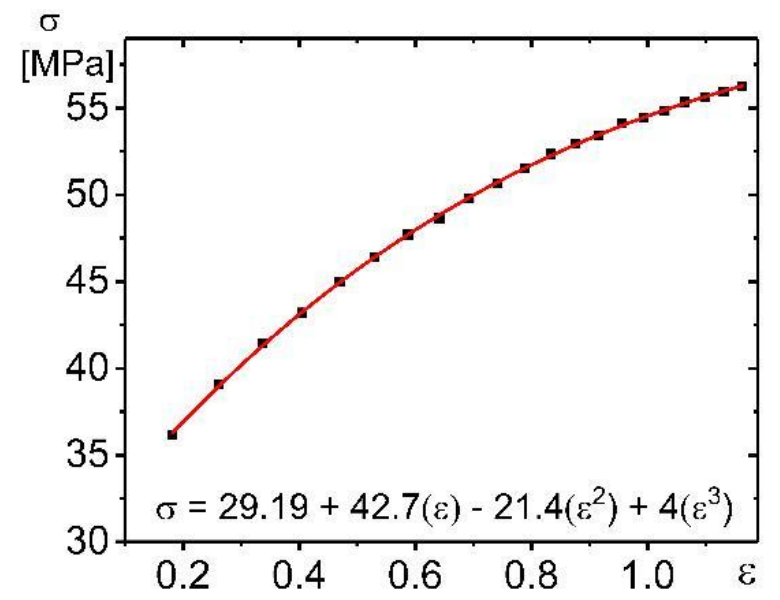

Fig. 8. Dependence of $\sigma$ versus $\varepsilon$ at reference conditions.

\subsubsection{C determination.}

The value of constant $\mathrm{C}$ was determined by ignoring the thermal softening term at the reference temperature $800{ }^{\circ} \mathrm{C}$. Therefore, Eq. 11 can be expressed as Eq. 13, $\sigma=\left(A_{1}+B_{1} \varepsilon+B_{2} \varepsilon^{2}+B_{3} \varepsilon^{3}\right)\left(1+C \ln \dot{\varepsilon}^{*}\right) \Rightarrow \frac{\sigma}{A_{1}+B_{1} \varepsilon+B_{2} \varepsilon^{2}+B_{3} \varepsilon^{3}}-1=C_{1} \ln \dot{\varepsilon}^{*}$ 
Fig.9 shows the dependence of $\frac{\sigma}{A_{1}+B_{1} \varepsilon+B_{2} \varepsilon^{2}+B_{3} \varepsilon^{3}}-1$ on $\ln \dot{\varepsilon}^{*}$. The material constant $\mathrm{C}$ was computed from the slop of the linear fitting at different strains Fig. 9a. The dependence of $\mathrm{C}$ vs. strain was fitted using Eq. 14 (Fig. 9b).

$$
C=1.24-1.96 \varepsilon+1.47 \varepsilon^{2}-0.58 \varepsilon^{3}
$$

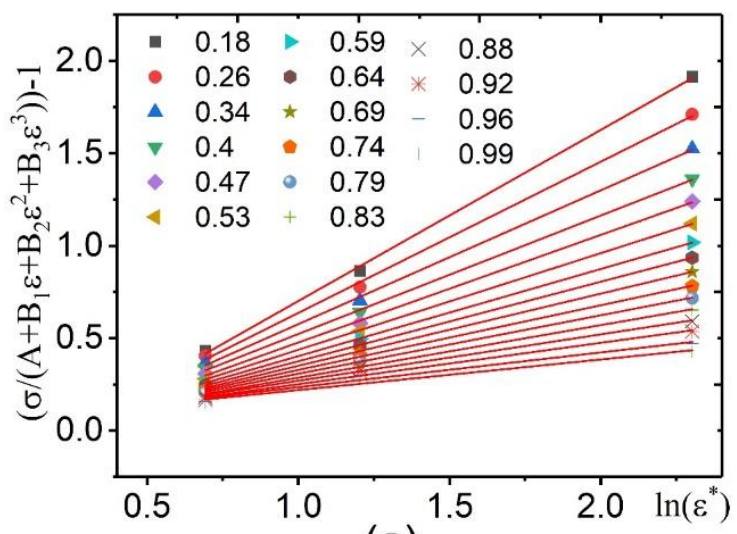

(a)

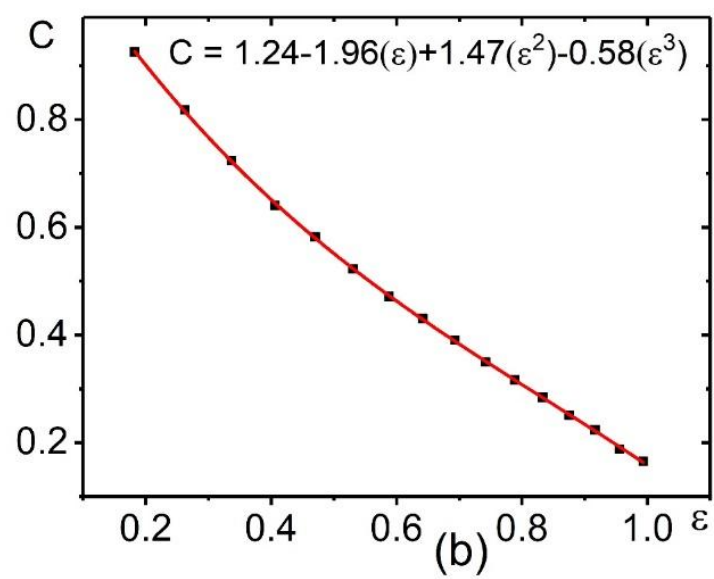

Fig. 9. (a) Relationship between $\frac{\sigma}{A_{1}+B_{1} \varepsilon+B_{2} \varepsilon^{2}+B_{3} \varepsilon^{3}}-1$ and $\ln \dot{\varepsilon}^{*}$ for strains of 0.1 to 1 and (b) strain dependence of $\mathrm{C}_{1}$.

\subsubsection{3. $\lambda$ determination.}

Considering the effect of thermal softening and strain rate hardening, Eq. 11 can be expressed as Eq.15,

$\frac{\sigma}{\left[\left(A_{1}+B_{1} \varepsilon+B_{2} \varepsilon^{2}+B_{3} \varepsilon^{3}\right)\left(1+\operatorname{Cln} \dot{\varepsilon}^{*}\right)\right]}=e^{\lambda\left(T-T_{r}\right)} \Rightarrow \ln \left(\frac{\sigma}{\left[\left(A_{1}+B_{1} \varepsilon+B_{2} \varepsilon^{2}+B_{3} \varepsilon^{3}\right)\left(1+\operatorname{Cln} \dot{\varepsilon}^{*}\right)\right]}\right)=\lambda\left(T-T_{r}\right)$

The plots of $\ln \left(\frac{\sigma}{\left[\left(A_{1}+B_{1} \varepsilon+B_{2} \varepsilon^{2}+B_{3} \varepsilon^{3}\right)\left(1+C \ln \dot{\varepsilon}^{*}\right)\right]}\right)$ vs $T-T_{r}$ for strains from 0.1 to 1 at various temperatures are presented in Fig. 10a-d. The material constant $\lambda$ was obtained from the slope of the fitted plots for $\dot{\varepsilon}^{*}$ at $1,2,3.33$ and 10 with a strain range of 0.1 to 1 . The dependence of $\lambda$ vs strain at different $\dot{\varepsilon}^{*}$ was then fitted (Fig. 10e). The intercept and slope of these relationships are shown in Fig.10(f). The value of $\lambda$ expressed as Eq.16,

$$
\begin{aligned}
\lambda= & {\left[-0.01037-0.00511 \ln \dot{\varepsilon}^{*}+0.00202\left(\ln \dot{\varepsilon}^{*}\right)^{2}\right]+\left[+0.00569-0.0027 \ln \dot{\varepsilon}^{*}-\right.} \\
& \left.0.00103\left(\ln \dot{\varepsilon}^{*}\right)^{2}\right] \varepsilon
\end{aligned}
$$




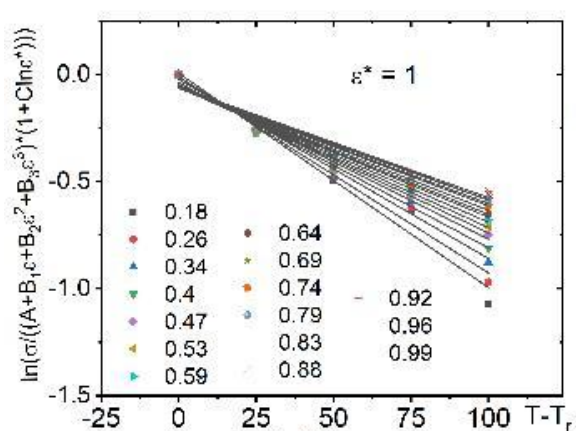

(a)
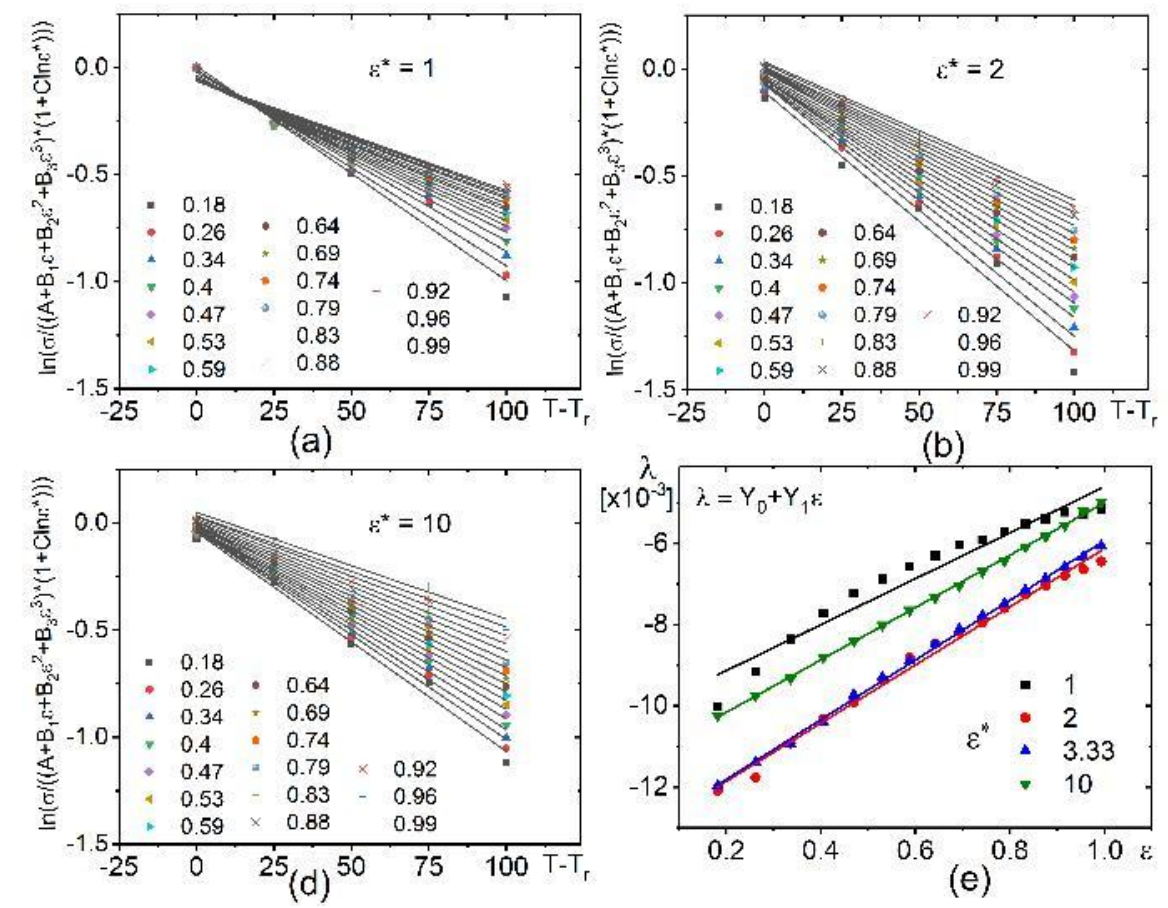

(b)

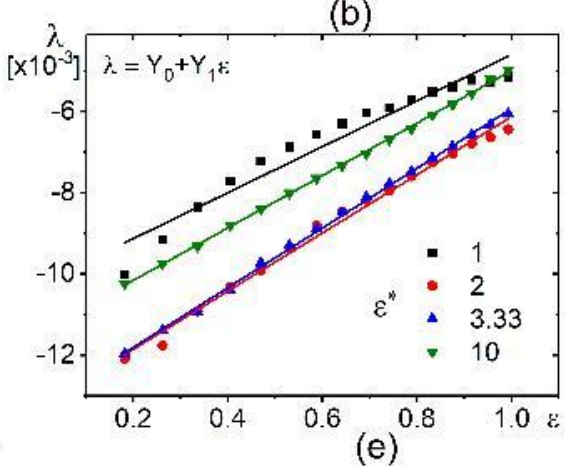

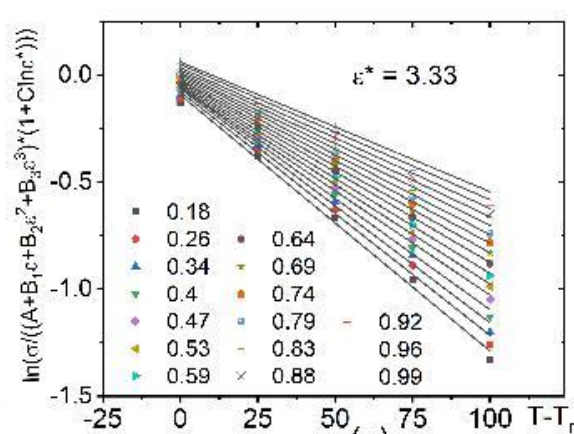

(c)

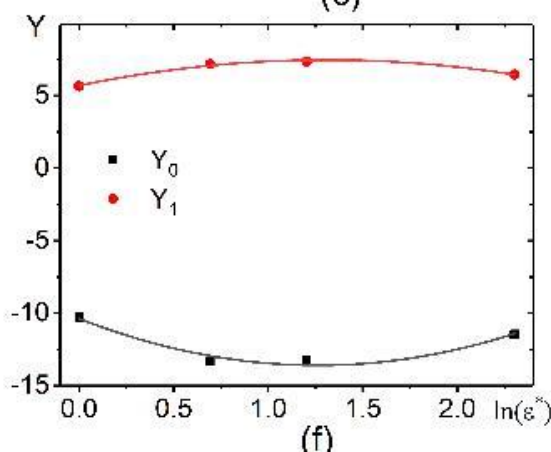

Fig. $10 \ln \left(\frac{\sigma}{\left[\left(A_{1}+B_{1} \varepsilon+B_{2} \varepsilon^{2}+B_{3} \varepsilon^{3}\right)\left(1+C \ln \dot{\varepsilon}^{*}\right)\right]}\right)$ vs $T-T_{r}$ for strains from 0.1 to 1 at (a) $\dot{\varepsilon}^{*}=1$, (b) $\dot{\varepsilon}^{*}=2$, (c) $\dot{\varepsilon}^{*}=3$, and (d) $\dot{\varepsilon}^{*}=10$, (e) $\lambda$ vs strain at deferent $\dot{\varepsilon}^{*}$, and (f) intercept and slope $\lambda$ equation.

Thus, the relationship between $\sigma, \varepsilon, \dot{\varepsilon}$ and $\mathrm{T}$ can be expressed in terms of the flow stress, Eq. 17.

$\left\{\begin{array}{l}\sigma=\left[29.19+42.7 \varepsilon-21.4 \varepsilon^{2}+4 \varepsilon^{3}\right]\left[1+C \ln \frac{\dot{\varepsilon}}{0.0003}\right]\left[e^{\lambda(T-800)}\right. \\ C=1.24-1.96 \varepsilon+1.47 \varepsilon^{2}-0.58 \varepsilon^{3} \\ \lambda=\left[-0.01037-0.00511 \ln \dot{\varepsilon}^{*}+0.00202\left(\ln \dot{\varepsilon}^{*}\right)^{2}\right]+\left[+0.00569-0.0027 \ln \dot{\varepsilon}^{*}-0.00103\left(\ln \dot{\varepsilon}^{*}\right)^{2}\right] \varepsilon\end{array}\right.$ (17)

The correlation between the experimental and predicted flow stresses is shown in Fig. 11.

The values of the statistical comparative quantities R, AARE and RMSE after M J-C model are $98 \%, 4.4 \%$ and 2.5, respectively. The values reflect a good matching between the experimental and predicted flow behavior of this alloy. Therefore, the M J-C model offers a better approach for fitting and predicting the flow behavior of Ti-6Al-4V alloy in juxtaposition to the S J-C model. 

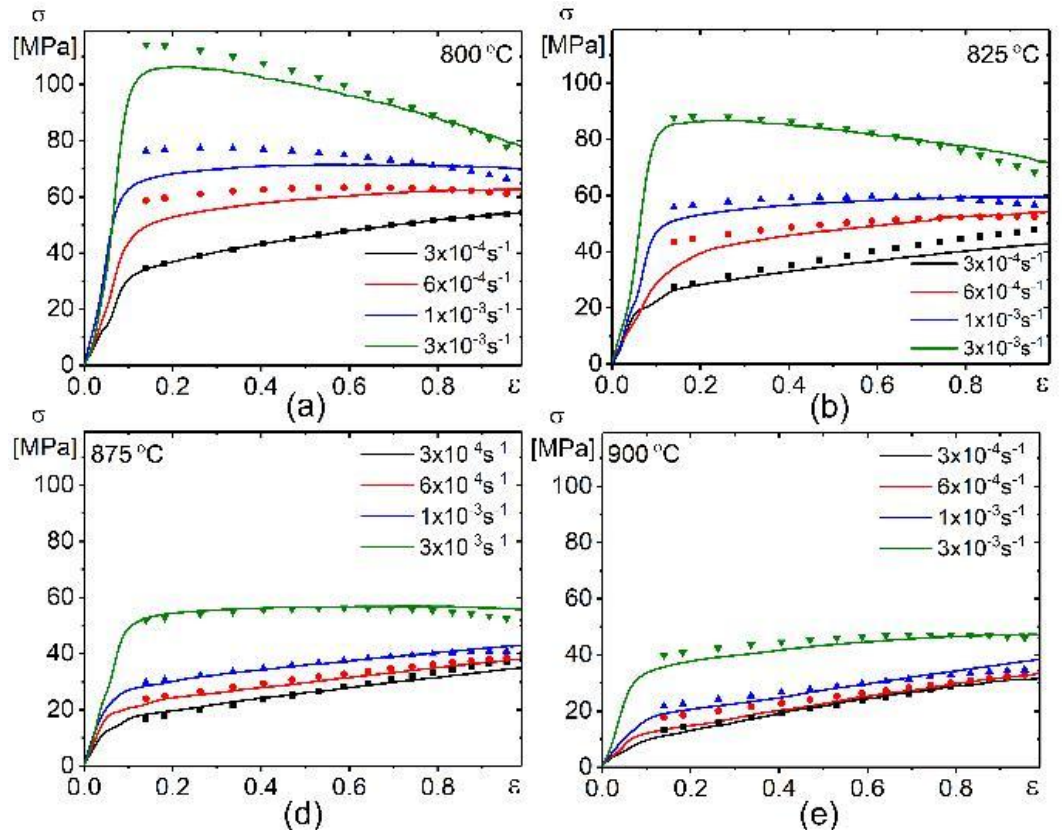

(e)
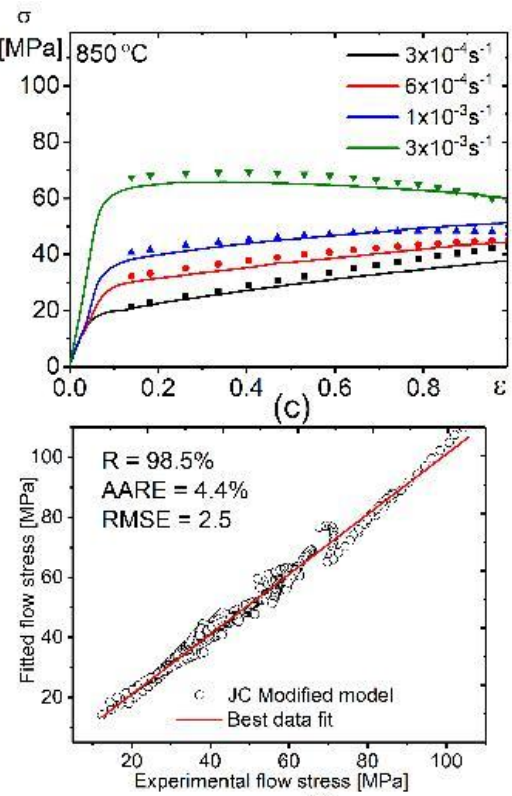

(f)

Fig. 11. Comparative plots for the experimental results (lines) and fitted values by M J-C model (symbols) at various strain rates and temperatures; (a) $800{ }^{\circ} \mathrm{C}$, (b) $825{ }^{\circ} \mathrm{C}$, (c) $850{ }^{\circ} \mathrm{C}$, (d) $875^{\circ} \mathrm{C}$, (e) $900{ }^{\circ} \mathrm{C}$ and (f) the correlation between experimental and fitted flow stresses.

\subsubsection{Artificial neural network analysis (ANN)}

A three-layered Back- Propagation (BP) ANN was constructed to fit and predict the flow stress behavior of the investigated alloy. The used ANN architecture is presented in Fig. 12. Before training the proposed ANN model, the training data were normalized within a range $(0,1)$ to achieve the standard form that could be correctly read. The normalization equation is expressed as in (Eq. 19) [41,42].

$$
W=\frac{Y-0.95 Y_{\min }}{1.05 Y_{\max }-0.95 Y_{\min }}
$$

where $Y, Y_{\min }$ and $Y_{\max }$ are the tested data value, the minimum, and the maximum values of the tested data, respectively. $W$ is the related data equivalent to $Y$.

In the current study, a typical architecture of the ANN model consisting of three layers was constructed. There was an input layer having three parameters (strain, deformation temperature and strain rate), a single hidden layer with 20 neurons [43] and an output layer. The transfer functions of the hidden and output layers were 'tan-sigmoid' and 'pure linear', respectively. The constructed ANN was trained using the feed forward BP algorithm. Neural network toolbox of MATLAB 2015b was used to construct this model. 


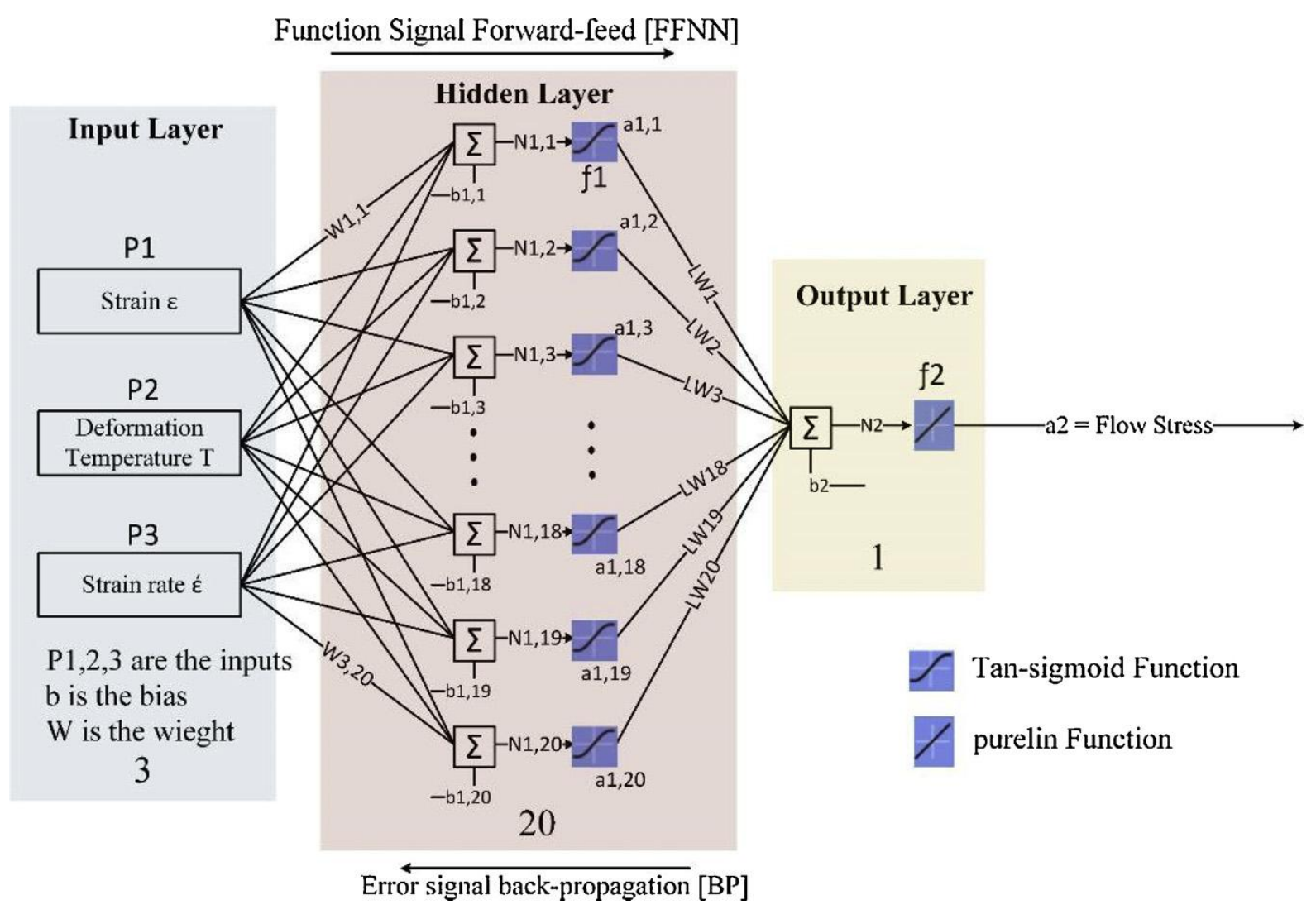

Fig. 12. Schematic of the ANN architecture used with one hidden layer.

The goal of the mean square error (MSE) was set as $10^{-6}$ in the constructed network training. The epoch is known to be the one complete pass through an arrangement of inlet-target couples throughout the network training [27]. After approximately 8000 epochs, the errors were stabilized. It is in agreement with [27,43]. Fig. 13a-e shows the plots of the tested (lines) and approximations (scatters) by ANN model flow stress. Fig. 13f shows the performance of the constructed model. Fig. 13 reveals that, the flow stress of the investigated alloy can be accurately fitted and approximated by the ANN model. The approximated flow stress is in an excellent agreement with the tested stress results. The R, AARE and RMSE values are $99.9 \%, 0.2 \%$ and 0.2 (Fig. 13f), respectively. Therefore, ANN proves to be a suitable model for fitting the flow stress behavior of Ti- $6 \% \mathrm{Al}-4 \% \mathrm{~V}$ alloy. The flow behavior in this alloy can be precisely modelled by both $\mathrm{M} \mathrm{J}-\mathrm{C}$ and ANN models. In the case of S J-C model, the level of error was very high compared with those from M J-C and ANN models, hence their poor ability to model the flow behavior. This makes the adoption of SJC model for the flow behavior prediction in $\mathrm{Ti}-6 \% \mathrm{Al}-4 \% \mathrm{~V}$ alloy very cumbersome. 

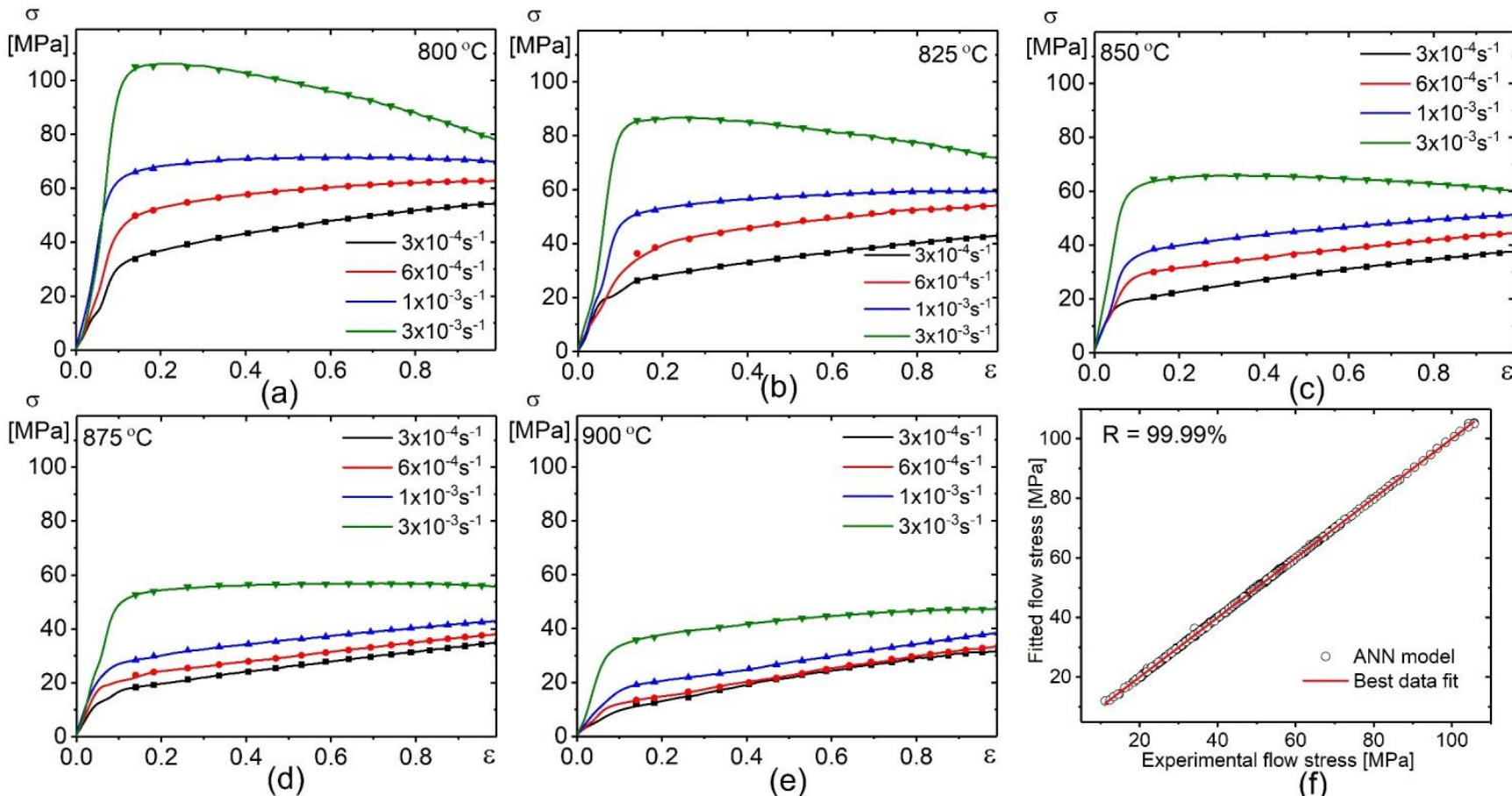

Fig. 13 Comparative plots for the experimental results (lines) and fitted values by ANN model (symbols) at various strain rate and temperatures; (a) $800{ }^{\circ} \mathrm{C}$, (b) $825^{\circ} \mathrm{C}$, (c) $850{ }^{\circ} \mathrm{C}$, (d) $875^{\circ} \mathrm{C}$, (e) $900{ }^{\circ} \mathrm{C}$ and (f) the correlation between experimental and fitted flow stress.

\subsection{Finite element simulation (FES)}

Finite element simulation was performed in order to ascertain the forming process parameters of this alloy (pressure-time dependence) as well as to predict the cross-section thickness distribution after the forming process. The FE simulation was performed using a commercial FE package, DEFORM 3D. The flow stress at hot deformation of the investigated alloy can be set in this program on the bases of the experimental or predicted data obtained from the constructed models. The flow stress can be expressed as a function of strain rate and temperature $\left(\sigma=\mathrm{f}\left(\varepsilon^{*}, \varepsilon, \mathrm{T}\right)\right)$ or by considering the obtained models' constants. The results of the FES are a consequence of the entered data. Therefore, the more accurate the constructed models, the more accurate the FES results. During the simulation process, the forming gas pressure was set in order to ensure that, the optimum forming conditions were consistent with the $2 \times 10-3 \mathrm{~s}-1$ strain rate (Fig. 14a). Seven control points (P1-P7) were placed on the meshed blank specimen as shown in Fig. 14b. The evolution of strain rates in different control points with respect to the normalized strain was analyzed. The results show that, the strain rates at the selected points are close to the value of $2 \times 10-3 \mathrm{~s}-1$. The sharp decrease in strain rate in the graph corresponds with the contact of the control point to the die surface. P4 and P7 are the first and last formed points, respectively. 


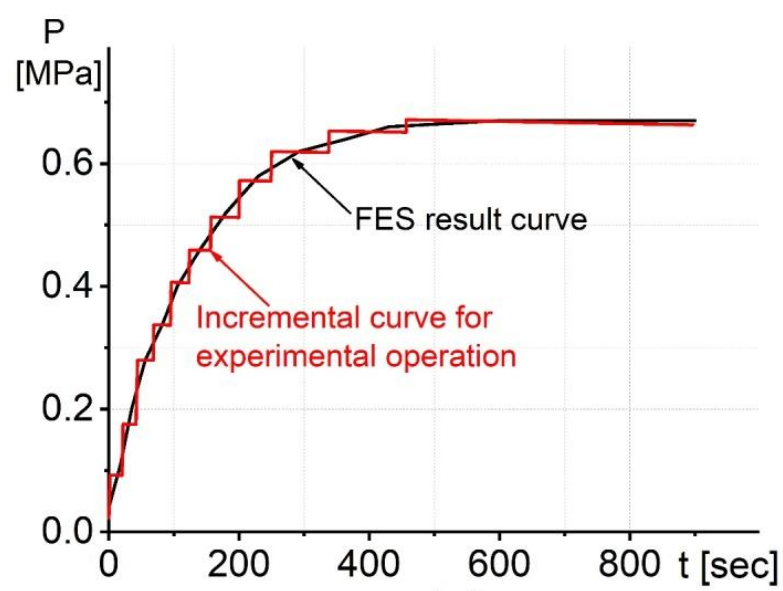

(a)

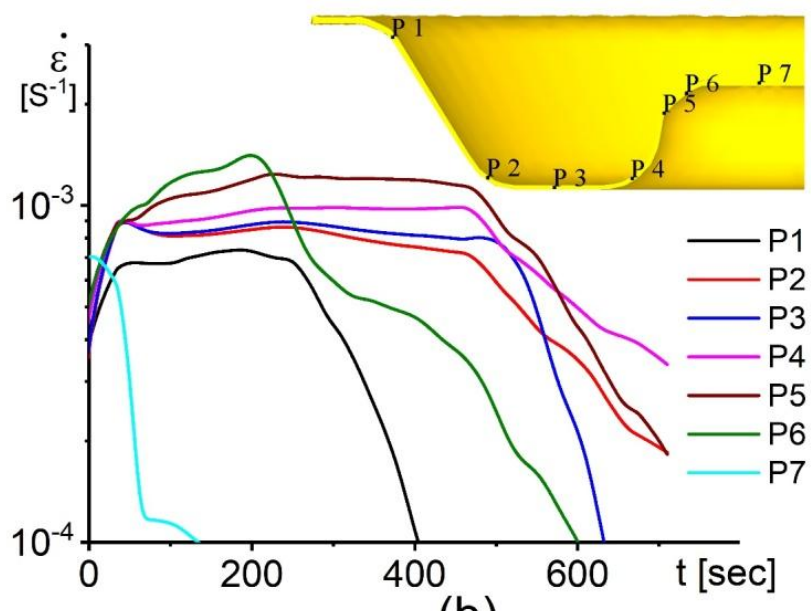

(b)

Fig. 14 Finite element simulation results of the investigated alloy (a) optimum pressure versus time corresponding to $2 \times 10^{-3} \mathrm{~s}^{-1}$ strain rate and (b) strain rate versus time at different tracking points.

\subsection{Superplastic forming (SPF) process}

SP forming of the investigated alloy was performed in a superplastic forming lab machine at a temperature of $875 \pm 5{ }^{\circ} \mathrm{C}$, which corresponds to the optimum forming temperature of the tested material. The die used was fabricated from cast iron and was lubricated using an NB liquid coating during the forming process.

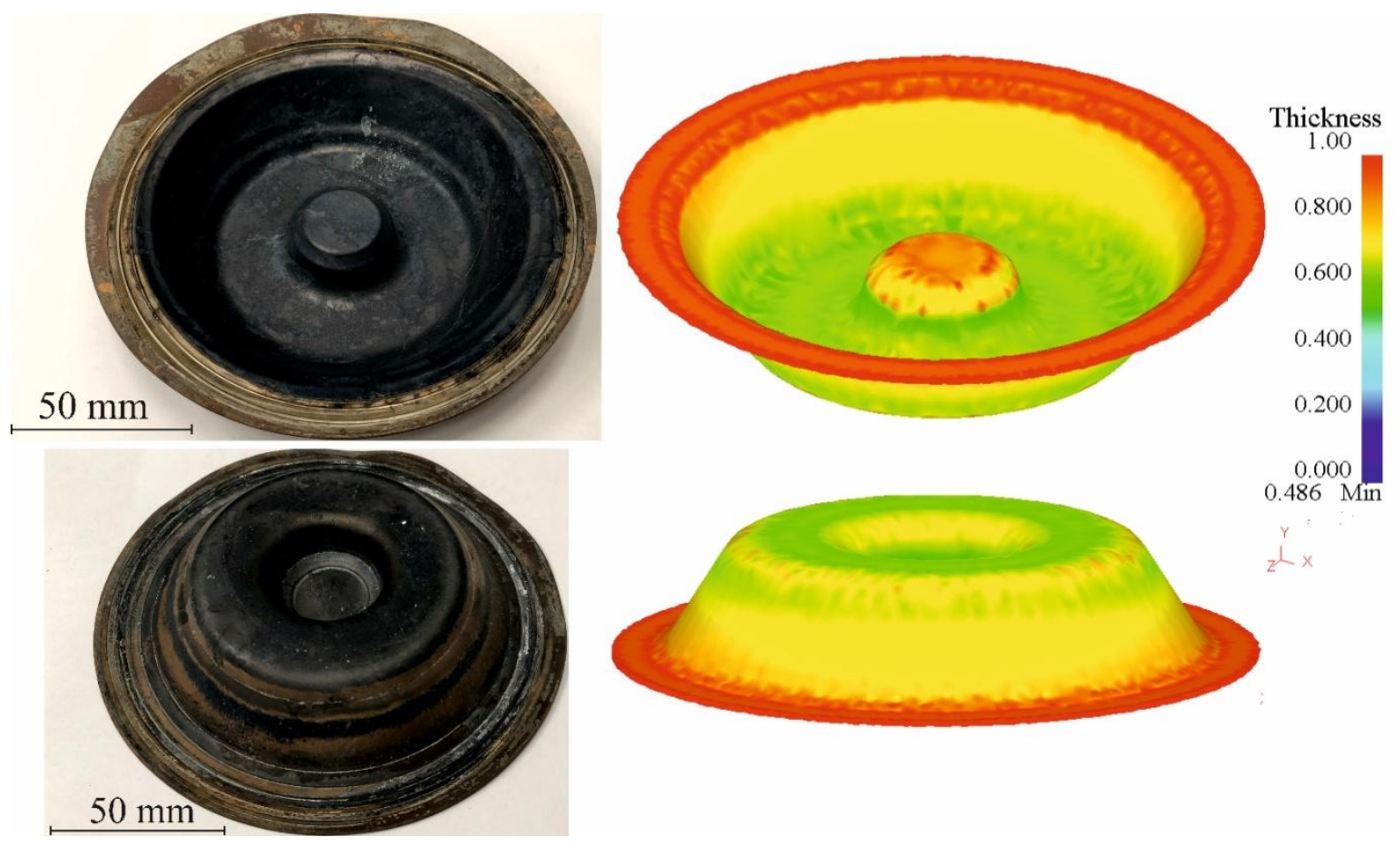

Fig. 15. Geometrical comparison of SPF with FES result of the investigated alloy. 
The dependence of forming gas pressure on the forming time, which corresponded to a strain rate of $2 \times 10-3 \mathrm{~s}-1$, was indicated after the FES phase. Incremental loading curve was applied to correct the curves determined by the FES due to the limited capability of the gas control cabinet (Fig. 14a). The sheets were shaped by gas-pressure bulging and the test was not stopped until the plate fitted the mold completely. The superplastic forming process took 15 min as determined by the FES. Fig. 15 illustrates a comparative study between the geometry of the parts obtained from FES and SPF. The result shows that, the SPF part is in excellent agreement with the simulated part. The FES can therefore be successfully adopted to simulate the part forming process. The predicted values of the final thickness of the simulated part at the control points were compared with the measured values of the formed part at the same points in order to verify the accuracy of the FES model (Fig. 16). The thickness distribution of the simulated part model was in good agreement with the formed part. The thickness values realized after the simulation were close to the experimental values with an average difference of about $8 \%$. The results obtained after FES of the investigated alloy proves the possibility of using uniaxial tensile test results to simulate the superplastic forming process of Ti-6\%Al-4\%V alloy.

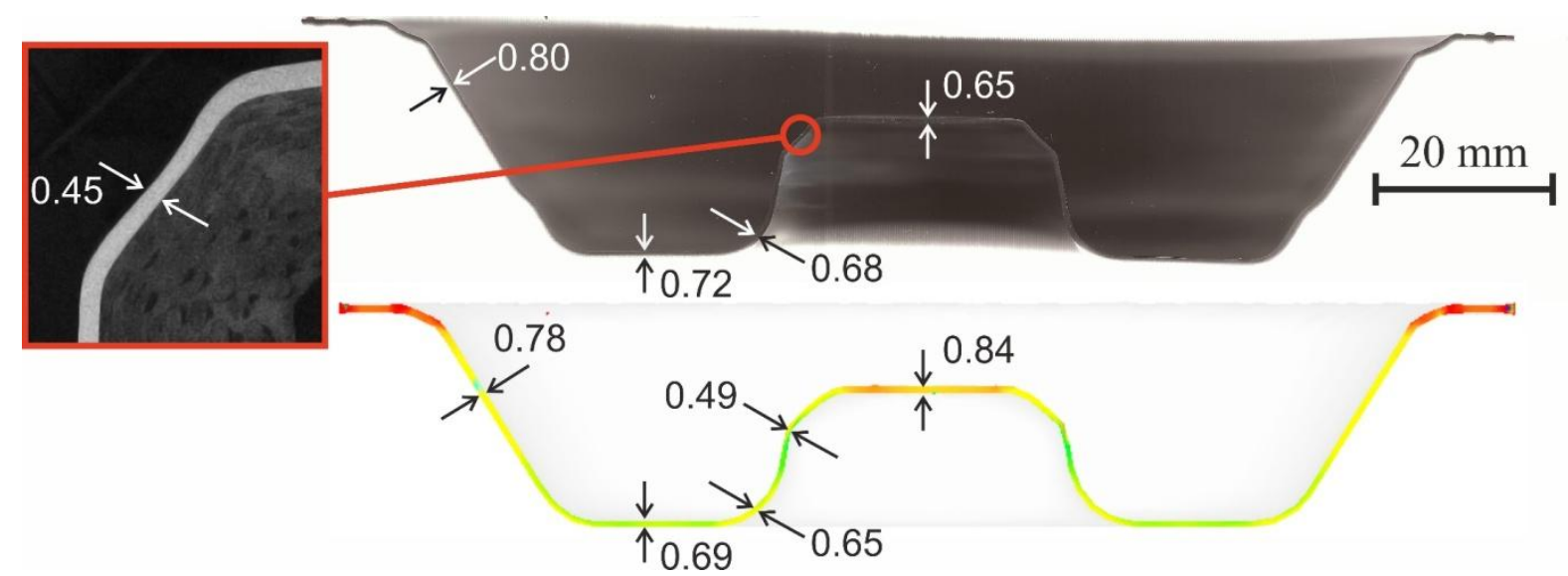

Fig. 16. Thickness distribution comparison of SPF with FES result of the investigated alloy.

Further analysis reveals that, the thickness was uniform across sections with strain variation from 0.40 to 0.45 except at the critical regions (Fig. 16). The strains attained at the critical region was up to 0.9 . These regions corresponded to P5 and P6, in which the strain rate had a maximum under the used forming condition. Generally, forming at $875{ }^{\circ} \mathrm{C}$ and $2 \times 10-3 \mathrm{~s}-1$ was appropriate for this alloy because under this condition, the cross-sectional thickness distribution was mostly uniform. 
Critical analysis after FES and SPF shows that, the constructed M J-C and ANN models correctly predict the flow behavior of Ti-6\% Al-4\% V alloy.

\subsection{Post-SPF analysis}

The microstructure evolution after superplastic forming process across the section and at critical points corresponding to the maximum strain was analyzed. Fig. 17 shows the microstructure after SPF of the investigated alloy. The microstructure analysis of the formed part reveals the uniformity of the thickness distribution, (Fig. 17a). There were no noticeable cavities after forming and the observed grains structure was fine and equiaxed. The resulting sizes of $\alpha$ - and $\beta$-grains were $3.4 \pm 0.3 \mu \mathrm{m}$ and $2.5 \pm 0.3 \mu \mathrm{m}$ respectively (Fig. 17b-e), which are considered favorable for superplastic forming of Ti alloys [2-4]. The forming process at $875^{\circ} \mathrm{C}$ and $2 \times 10-3 \mathrm{~s}-1$ made the strain vary across the section from 0.43 to 0.88 .
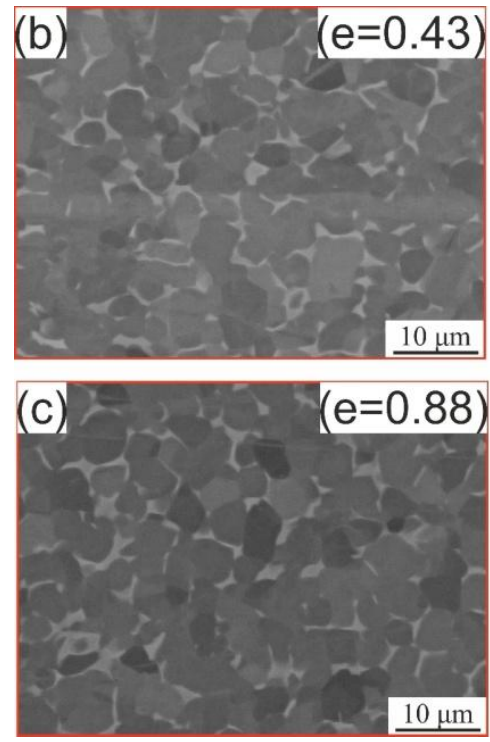
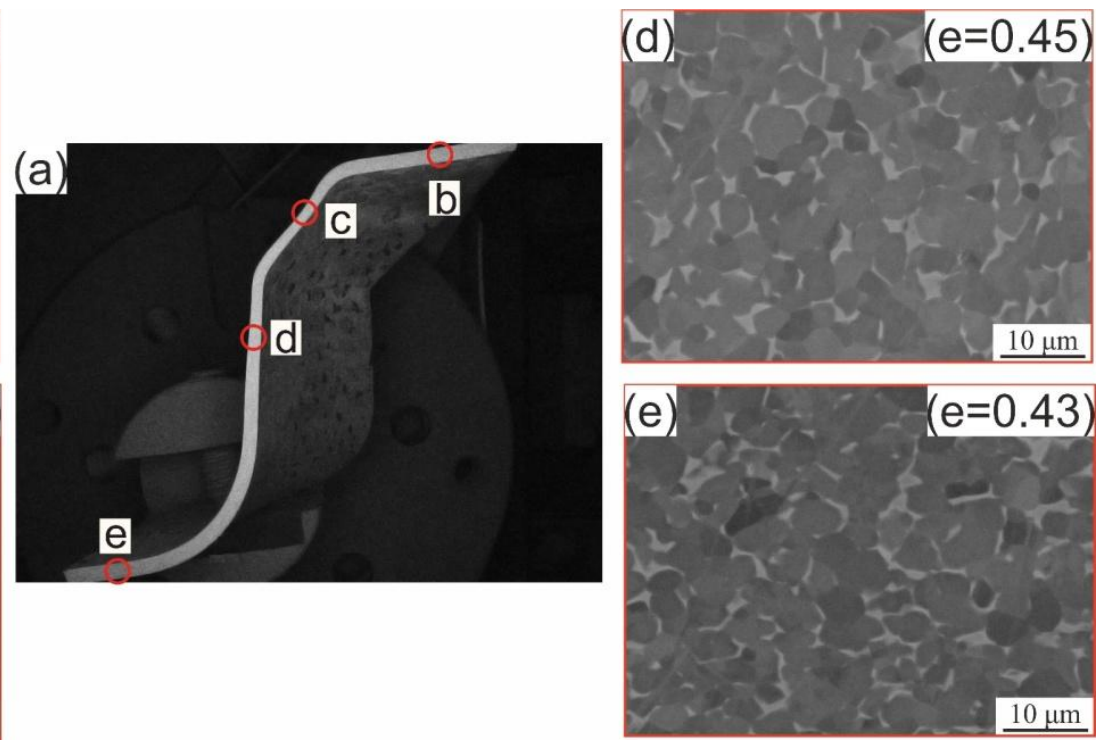

Fig. 17. Microstructural evolution during superplastic forming for the investigated alloy; (a)

Macrograph of the SPF part thickness; (b-e) - SEM microstructures corresponded with points marked up in (a)

\section{Conclusion}

This paper introduced an integrated approach for the successful superplastic forming of Ti$6 \% \mathrm{Al}-4 \% \mathrm{~V}$ titanium alloy. The proposed integrated approach consists of several steps; material characterization, flow behavior modeling, finite element simulation, superplastic forming and post-superplastic forming characterization. All these steps are related to each 
other. In the Material characterization step, the flow behavior of Ti-6\%Al- 4\% V alloy was characterized by strain hardening at all conditions except for strain rate at $3 \times 10-3 \mathrm{~s}-1$ and a temperature range of $800-850{ }^{\circ} \mathrm{C}$. The obtained flow behavior was modeled with different constitutive models; Simple Johnson-Cook (S J-C), Modified Johnson- Cook (M J-C), and Artificial neural network (ANN). The performance of each model was evaluated using comparative statistical terms. Based on these statistical terms, the S J-C model proved to be ineffective in describing the flow behavior of the investigated alloy because of the high level of obtained errors $(\mathrm{R}=80 \%, \mathrm{AARE}=26 \%$, and $\mathrm{RMSE}=13.2)$. The M J-C and ANN models produced low level of errors, $(\mathrm{R}=98 \%, \mathrm{AARE}=4.4 \%$, and $\mathrm{RMSE}=2.5$ for $\mathrm{M} \mathrm{J}-\mathrm{C} ; \mathrm{R}=99.9 \%$, $\mathrm{AARE}=0.2 \%$, and $\mathrm{RMSE}=0.2$ for $\mathrm{ANN}$ ) hence are able to successfully describe the flow behavior of $\mathrm{Ti}-6 \% \mathrm{Al}-4 \% \mathrm{~V}$ titanium alloy. After proving the accuracy of the constructed models, both the experimental and obtained data from these models were used to adjust the flow stress of Ti-6\%Al-4\%V titanium alloy with FES. The FES of the superplastic forming process was implemented and the complex shape parts were produced at the desired strain rate of $2 \times 10-3 \mathrm{~s}^{-1}$ and temperature of $875^{\circ} \mathrm{C}$. The strain rate attained across the formed part at various forming points was $2 \times 10^{-3} \mathrm{~s}^{-1}$. The required forming parameters (pressure-time dependence) were determined in the FES step and then utilized in the SPF step. The superplastic forming process was successfully carried out using a superplastic forming lab machine. The thickness evolution observed in the parts after SPF was consistent with those observed after FES with deviation less than $8 \%$. Therefore, this approach can be effectively utilized for predicting the SPF parameters such as forming thickness distribution, forming time and the optimization of pressure profile. The microstructure of the studied alloy after superplastic forming was fairly uniform with the grains maintaining their equiaxed shape in a strain range of $0.43-0.88$.

\section{Declaration of interests}

The authors declare that they have no known competing financial interests or personal relationships that could have appeared to influence the work reported in this paper.

\section{Acknowledgements}

The study was supported by Russian Science Foundation Grant \#18- 79-00348. We wish to dedicate this work to the memory of Prof. V.K. Portnoy. We are extremely thankful for his 
guidance, patience and support. He was always nice, calm, and he taught us how to be always optimistic, even in the dark.

References

[1] Boyer RR. Titanium for aerospace: rationale and applications. Adv Perform Mater 1995;2:349-68. https://doi.org/10.1007/BF00705316.

[2] Leyens C, Peters M. Titanium and titanium alloys. England: John Wiley \& Son Inc; 2002. https://doi.org/10.1002/3527602119.

[3] Moiseyev VN. Titanium alloys: Russian aircraft and aerospace applications. 2006. https://doi.org/10.1017/CBO9781107415324.004.

[4] Nieh TG, Wadsworth J, Sherby OD. Superplasticity in metals and ceramics. Cambridge University Press; 2014. https://doi.org/10.1007/s13398-014-0173-7.2.

[5] Zhang ZX, Qu SJ, Feng AH, Shen J, Chen DL. Hot deformation behavior of Ti-6Al-4V alloy: effect of initial microstructure. J Alloys Compd 2017;718:170-81. https:// doi.org/10.1016/j.jallcom.2017.05.097.

[6] Alabort E, Putman D, Reed RC. Superplasticity in Ti-6A-4V : Characterisation, modelling and applications. Acta Mater 2015;95:428-42. https://doi.org/10.1016/ j.actamat.2015.04.056.

[7] Mosleh AO, Mikhaylovskaya AV, Kotov AD, Abushanab WS, Moustafa EB, Portnoy VK. Experimental Investigation of the Effect of Temperature and Strain Rate on the Superplastic Deformation Behavior of Ti-Based Alloys in the $(\alpha+\beta)$ Temperature Field. Metals (Basel) 2018. https://doi.org/10.3390/met8100819.

[8] Homporová P, Poletti C, Stockinger M, Warchomicka F. Dynamic phase evolution in titanium alloy Ti-6Al-4V. 12th World Conf Titanium, Beijing, China; Zhou, L. 2011. p. 1942.

[9] Zherebtsov SV, Kudryavtsev EA, Salishchev GA, Straumal BB, Semiatin SL. Microstructure evolution and mechanical behavior of ultrafine Ti6Al4V during low temperature superplastic deformation. Acta Mater 2016;121:152-63. https://doi. org/10.1016/j.actamat.2016.09.003.

[10] Guo W, Jia Q, Li R, Li W. The superplastic deformation behavior and phase evolution of Ti-6Al-4V alloy at constant tensile velocity. High Temp Mater Process 2017;36:55-62. https://doi.org/10.1515/htmp-2015-0205.

[11] Motyka M, Sieniawski J, Ziaja W. Microstructural aspects of superplasticity in Ti-6Al4V alloy. Mater Sci Eng A 2014;599:57-63. https://doi.org/10.1016/j.msea.2014.01.067. 
[12] Alabort E, Kontis P, Barba D, Dragnevski K, Reed RC. On the mechanisms of superplasticity in Ti-6Al-4V. Acta Mater 2016;105:449-63. https://doi.org/10.1016/j.actamat.2015.12.003.

[13] Salishchev GA, Kudrjavtsev EA, Zherebtsov SV, Semiatin SL. Low temperature superplasticity of Ti-6Al-4V processed by warm multidirectional forging. 11th Int Conf Superplast Adv Mater ICSAM 2012 2013;735:253-8. 10.4028/www.scientific. net/MSF.735.253.

[14] Akihiko C. Superplasticity of the ultrafine-grained Ti-6A Al-4V alloy with a metastable -single phase microstructure. Proc 13th World Conf Titan. 2016. p. 789-92.

[15] Mikhaylovskaya AV, Mosleh AO, Kotov AD, Kwame JS, Pourcelot T, Golovin IS, et al. Superplastic deformation behaviour and microstructure evolution of near- $\alpha$ Ti-Al-Mn alloy. Mater Sci Eng A 2017;708:469-77. https://doi.org/10.1016/j.msea.2017.10.017.

[16] Zhang T, Liu Y, Sanders DG, Liu B, Zhang W, Zhou C. Development of fine-grain size titanium $6 \mathrm{Al}-4 \mathrm{~V}$ alloy sheet material for low temperature superplastic forming. Mater Sci Eng A 2014;608:265-72. https://doi.org/10.1016/j.msea.2014.04.098.

[17] Kotov AD, Mikhailovskaya AV, Mosleh AO, Pourcelot TP. Superplasticity of an Ultrafine-Grained $\mathrm{Ti}-4 \% \mathrm{Al}-1 \% \mathrm{~V}-3 \%$ Mo Titanium Alloy. Phys Met Metallogr 2019;120:66-74. https://doi.org/10.1134/S0031918X18100083.

[18] Mosleh AO, Mikhaylovskaya AV, Kotov AD, Kwame JS, Aksenov SA. Superplasticity of Ti-6Al-4V Titanium Alloy: Microstructure Evolution and Constitutive Modelling. Materials (Basel) 2019;12:1756. https://doi.org/10.3390/ma12111756.

[19] Cui Z, Zhu H, Ren F, Chen F, Wang H, Zhu H. High-temperature deformation mechanisms and physical-based constitutive modeling of ultra-supercritical rotor steel. $\mathbf{J}$ Manuf Process 2019;38:223-34. https://doi.org/10.1016/j.jmapro.2019.01.021.

[20] Peng W, Zeng W, Wang Q, Yu H. Comparative study on constitutive relationship of ascast Ti60 titanium alloy during hot deformation based on Arrhenius-type and artificial neural network models. Mater Des 2013;51:95-104. https://doi.org/10. 1016/j.matdes.2013.04.009.

[21] Mosleh AO, Mikhaylovskaya AV, Kotov AD, Portnoy VK. Arrhenius-type constitutive equation model of superplastic deformation behaviour of titanium-based alloys. 2018. 10.4028/www.scientific.net/DDF.385.45.

[22] Sun Y, Zeng WD, Zhao YQ, Qi YL, Ma X, Han YF. Development of constitutive relationship model of Ti600 alloy using artificial neural network. Comput Mater Sci 2010;48:686-91. https://doi.org/10.1016/j.commatsci.2010.03.007.

[23] He J, Chen F, Wang B, Zhu LB. A modified Johnson-Cook model for 10\%Cr steel at elevated temperatures and a wide range of strain rates. Mater Sci Eng A 2018;715:1-9. https://doi.org/10.1016/j.msea.2017.10.037. 
[24] Lei X, Zhang Z, Sha Y, Hu M, Yang R, Dong L. Correction of flow curves and constitutive modelling of a Ti-6Al-4V alloy. Metals (Basel) 2018;8:256. https://doi.org/ 10.3390/met8040256.

[25] Reddy NS, Lee YH, Park CH, Lee CS. Prediction of flow stress in Ti-6Al-4V alloy with an equiaxed $\alpha+\beta$ microstructure by artificial neural networks. Mater Sci Eng A 2008;492:276-82. https://doi.org/10.1016/j.msea.2008.03.030.

[26] Sun Y, Zeng WD, Zhao YQ, Zhang XM, Shu Y, Zhou YG. Modeling constitutive relationship of Ti40 alloy using artificial neural network. Mater Des 2011;32:1537-41. https://doi.org/10.1016/j.matdes.2010.10.004.

[27] Zhao J, Ding H, Zhao W, Huang M, Wei D, Jiang Z. Modelling of the hot deformation behaviour of a titanium alloy using constitutive equations and artificial neural network. Comput Mater Sci 2014;92:47-56. https://doi.org/10.1016/j. commatsci.2014.05.040.

[28] Li HY, Wei DD, Li YH, Wang XF. Application of artificial neural network and constitutive equations to describe the hot compressive behavior of $28 \mathrm{CrMnMoV}$ steel. Mater Des 2012;35:557-62. https://doi.org/10.1016/j.matdes.2011.08.049.

[29] Haghdadi N, Zarei-Hanzaki A, Khalesian AR, Abedi HR. Artificial neural network modeling to predict the hot deformation behavior of an A356 aluminum alloy. Mater Des 2013;49:386-91. https://doi.org/10.1016/j.matdes.2012.12.082.

[30] Ji G, Li F, Li Q, Li H, Li Z. A comparative study on Arrhenius-type constitutive model and artificial neural network model to predict high-temperature deformation behaviour in Aermet100 steel. Mater Sci Eng A 2011;528:4774-82. https://doi.org/10.1016/j.msea.2011.03.017.

[31] Hajari A, Morakabati M, Abbasi SM, Badri H. Constitutive modeling for hightemperature flow behavior of Ti-6242S alloy. Mater Sci Eng A 2017;681:10313.https://doi.org/10.1016/j.msea.2016.11.002.

[32] Lafeng G, Bao Cheng L, Yong X, Zhimin Z. Constitutive relationship model of Al-W alloy using artificial neural network. Adv Mater Res 2014;1004-1005:11204.10.4028/www.scientific.net/AMR.1004-1005.1120.

[33] Sabokpa O, Zarei-Hanzaki A, Abedi HR, Haghdadi N. Artificial neural network modeling to predict the high temperature flow behavior of an AZ81 magnesium alloy. Mater Des 2012;39:390-6. https://doi.org/10.1016/j.matdes.2012.03.002.

[34] Han Y, Qiao G, Sun J, Zou D. A comparative study on constitutive relationship of as cast $904 \mathrm{~L}$ austenitic stainless steel during hot deformation based on Arrhenius-type and artificial neural network models. Comput Mater Sci 2013;67:93-103. https://doi.org/10.1016/j.commatsci.2012.07.028. 
[35] Guo LF, Li BC, Zhang ZM. Constitutive relationship model of TC21 alloy based on artificial neural network. Trans Nonferrous Met Soc China (English Ed) 2013;23:1761-5. https://doi.org/10.1016/S1003-6326(13)62658-8.

[36] Zhen A, Jinshan L, Yong F, Xianghong L, Yuxuan D, Fanjiao M, et al. Modeling constitutive relationship of Ti-555211 alloy by artificial neural network during hightemperature deformation. Rare Met Mater Eng 2015;44:62-6. https://doi.org/10.1016/S18755372(15)30013-8.

[37] Sorgente D, Tricarico L. The role of the numerical simulation in superplastic forming process analysis and optimization. Key Eng Mater 2010;433:22534.10.4028/www.scientific.net/KEM.433.225.

[38] Luckey SG, Friedman PA, Weinmann KJ. Correlation of finite element analysis to superplastic forming experiments. J Mater Process Technol 2007;194:30-7. https://doi.org/10.1016/j.jmatprotec.2007.03.122.

[39] Giuliano G. Constitutive equation for superplastic Ti-6Al-4V alloy. Mater Des 2008;29:1330-3. https://doi.org/10.1016/j.matdes.2007.07.001.

[40] Chen Y, Kibble K, Hall R, Huang X. Numerical analysis of superplastic blow forming of Ti-6Al-4V alloys. Mater Des 2001;22:679-85. https://doi.org/10.1016/S02613069(01)00009-7.

[41] Kallassy A. A new neural network for response estimation. Comput Struct 2003;81:2417-29. https://doi.org/10.1016/S0045-7949(03)00320-1.

[42] Wu SW, Zhou XG, Cao GM, Liu ZY, Wang GD. The improvement on constitutive modeling of $\mathrm{Nb}-\mathrm{Ti}$ micro alloyed steel by using intelligent algorithms. Mater Des 2017;116:676-85. https://doi.org/10.1016/j.matdes.2016.12.058.

[43] Mosleh A, Mikhaylovskaya A, Kotov A, Pourcelot T, Aksenov S, Kwame J, et al. Modelling of the superplastic deformation of the Near- $\alpha$ titanium alloy (Ti-2.5Al-1.8Mn) using arrhenius-type constitutive model and artificial neural network.Metals (Basel) 2017;7:568. https://doi.org/10.3390/met7120568. 